\title{
Multigenerational Independent Colony for Extraterrestrial Habitation, Autonomy, and Behavior health (MICEHAB): An investigation of a long duration, partial gravity, autonomous rodent colony
}

\author{
Erica M. Rodgers, Matthew A. Simon† Jeffrey Antol, Patrick R. Chaił \\ Christopher A. Jonesł Jordan J. Klovstad, James H. Neilan, Fred H. Stillwagen* \\ and Phillip A. Williams \\ NASA Langley Research Center, Hampton, VA, 23681-2199, USA \\ Michael Bednarall \\ Purdue University, West Lafayette, IN 47907 \\ Alex Guendel ${ }^{\|}$ \\ Eastern Virginia Medical School, Norfolk, VA 23507 \\ Joel Hernandez" \\ Florida International University, Miami, FL, 33199 \\ Weston Lewis" \\ University of Nebraska-Lincoln, Lincoln, NE 68588 \\ Jeremy Lim** \\ Pennsylvania State University, State College, PA 16801 \\ Logan Wilson" \\ University of Maryland, College Park, MD 20742 \\ Grace Wusk" \\ University of Virginia, Charlottesville, VA 22904
}

\begin{abstract}
The path from Earth to Mars requires exploration missions to be increasingly Earthindependent as the foundation is laid for a sustained human presence in the following decades. NASA pioneering of Mars will expand the boundaries of human exploration, as a sustainable presence on the surface requires humans to successfully reproduce in a partial gravity environment independent from Earth intervention. Before significant investment is made in capabilities leading to such pioneering efforts, the challenges of multigenerational mammalian reproduction in a partial gravity environment need be investigated. The Multigenerational Independent Colony for Extraterrestrial Habitation, Autonomy, and Behavior health is designed to study these challenges. The proposed concept is a conceptual, long duration, autonomous habitat designed to house rodents in a partial gravity environment with the goal of understanding the effects of partial gravity on mammalian reproduction over multiple generations and how to effectively design such a facility to operate autonomously
\end{abstract}

*Aerospace Engineer, Space Mission Analysis Branch, MS 462, 1 North Dryden Street, Hampton, VA

$\dagger$ †erospace Engineer, Space Mission Analysis Branch, MS 462, 1 North Dryden Street, Hampton, VA, AIAA Senior Member

$\ddagger$ Aerospace Engineer, Space Mission Analysis Branch, MS 462, 1 North Dryden Street, Hampton, VA, AIAA Member.

§Software Engineer, Flight Software Systems Branch, MS 492, 1 North Dryden Street, Hampton, VA

『Research Physicist, Nondestructive Evaluation Sciences Branch, MS 231, 1 North Dryden Street, Hampton, VA

"NASA Intern, Space Mission Analysis Branch, MS 462, 1 North Dryden Street, Hampton, VA

**NASA Intern, Flight Software Systems Branch, MS 492, 1 North Dryden Street, Hampton, VA 
while keeping the rodents healthy in order to achieve multiple generations. All systems are designed to feed forward directly to full-scale human missions to Mars. This paper presents the baseline design concept formulated after considering challenges in the mission and vehicle architectures such as: vehicle automation, automated crew health management/medical care, unique automated waste disposal and hygiene, handling of deceased crew members, reliable long-duration crew support systems, and radiation protection. This concept was selected from an architectural trade space considering the balance between mission science return and robotic and autonomy capabilities. The baseline design is described in detail including: transportation and facility operation constraints, artificial gravity system design, habitat design, and a full-scale mock-up demonstration of autonomous rodent care facilities. The proposed concept has the potential to integrate into existing mission architectures in order to achieve exploration objectives, and to demonstrate and mature common capabilities that enable a range of destinations and missions.

\section{Nomenclature}

\begin{tabular}{|c|c|}
\hline AEON & Autonomous Entity Operations Network \\
\hline AI & Autonomy Incubator \\
\hline BREED & Breeding Rodents Extraterrestrially to Enable Discovery \\
\hline C3 & Characteristic Energy \\
\hline ECLSS & Environmental Control and Life Support System \\
\hline EMC & Evolvable Mars Campaign \\
\hline EPSCoR & Experimental Program to Stimulate Competitive Research \\
\hline GCR & Galactic Cosmic Rays \\
\hline GLACIER & General Laboratory Active Cryogenic ISS Experiment Refrigerator \\
\hline GNC & Guidance, Navigation, and Control \\
\hline HLBL & High-Level Behavior Layer \\
\hline ISS & International Space Station \\
\hline ITU & International Telecommunications Union \\
\hline LED & Light Emitting Diode \\
\hline LEO & Low Earth Orbit \\
\hline LDRO & Lunar Distant Retrograde Orbit \\
\hline MICEHAB & $\begin{array}{l}\text { Multigenerational Independent Colony for Extraterrestrial Habitation, } \\
\text { Autonomy, and Behavior health }\end{array}$ \\
\hline $\mathrm{mT}$ & Metric Ton $(1,000 \mathrm{~kg})$ \\
\hline NEEMO & NASA Extreme Environment Mission Operations \\
\hline PCS & Power Control System \\
\hline RCS & Reaction Control System \\
\hline $\mathrm{RPM}$ & Rotation Per Minute \\
\hline SLS & Space Launch System \\
\hline SOA & State of the Art \\
\hline SPASIM & SPAcecraft SIMulator \\
\hline SPE & Solar Particle Events \\
\hline STS & Space Transportation System \\
\hline TCS & Thermal Control System \\
\hline
\end{tabular}

\section{Introduction}

The path from Earth to Mars requires exploration missions to be increasingly Earth-independent as the foundation is laid for a sustained human presence in the following decades. ${ }^{1,2}$ NASA is in the early stages of preparing to extend human presence beyond Low Earth Orbit (LEO) through missions conducted in cis-lunar 
space in the 2020's and to the Mars system in the mid-2030s ${ }^{2}$ that would eventually culminate in extended duration crewed missions on Mars' surface leading to a permanent Mars surface station. ${ }^{2}$ NASA's latest human exploration planning effort, the Evolvable Mars Campaign (EMC), follows this pioneering approach and designates the Proving Ground as the time domain in which missions beyond LEO will demonstrate increasing mission capabilities while reducing technical risks, in order to provide valuable experience with deep space operations as missions transition from "Earth-dependent" to "Earth-independent". ${ }^{2}$ The EMC architecture is used to identify critical technologies and capabilities that need to be developed and tested during the Proving Ground in order to enable human exploration missions and eventually settlement of Mars. $^{3,4}$

Autonomous and robotic systems capabilities are required to operate long duration habitation systems and to perform medical care for crew, integrated vehicle health management, spacecraft maintenance, and logistics management for surface missions, as well as in deep space. These capabilities are beyond the current state-of-the-art and are presently being analyzed within the EMC architecture. NASA pioneering of Mars will utilize these autonomous and robotic systems capabilities to expand the boundaries of human exploration, as a sustainable presence on the surface requires humans to successfully reproduce and mature in a partial gravity environment independent from Earth intervention. Humans may encounter reproductive challenges in gravity environments different than Earth's, as gravitational forces may actively shape genomes in ways that are inheritable. ${ }^{3}$ The challenges associated with partial gravity, multigenerational human reproduction and spacecraft autonomy need be investigated prior to making investments in surface architecture efforts. Permanent surface settlements may be infeasible if partial gravity reproduction challenges are too great to overcome, leading to alternative strategies that focus on orbiting planetary facilities that simulate gravity more representative of Earth.

To date, research efforts have focused on better understanding the effects of microgravity on mammalian reproduction. Short duration mammalian life cycle experiments conducted aboard the Space Shuttle, and subsequent long duration experiments conducted and planned aboard the International Space Station (ISS) provide insight into challenges associated with mammalian reproduction and maturation in microgravity as compared to Earth's gravity. This research is rodent based, as a mammalian model focused on rodents provides significant potential for advancing translational knowledge applicable to future human settlements on Mars. The importance of using rodents as human analogs is echoed in the National Research Council's 2011 Decadal Survey where reproductive and developmental biology research and generational studies of rodents are discussed as high priority NASA initiatives. ${ }^{5}$

Microgravity studies of rodents over the past $30+$ years provide insight into the ways gravity may influence such factors as breeding, birthing, nursing/weaning, and offspring development. For example, no pregnancies were realized when rats were provided the opportunity to mate aboard the COSMOS 1129 satellite in 1979, although the male rats successful mated with new females post flight in $1 \mathrm{G} \cdot{ }^{6,7}$ Recent experiments conducted aboard Space Transportation System (STS) shuttle missions in 2010 and 2011 (STS-131, -133, and -135) using female mice suggest that the rats aboard COSMOS 1129 refused to mate or did not have eggs to fertilize due to decreased estrogen receptor levels experienced in microgravity. ${ }^{4,8}$

Nursing rat dams and their offspring flew in orbit for the first time on the National Institutes of HealthRodents (NIH.R3) and Neurolab missions aboard STS-72 in 1996 and STS-90 in 1998, respectively. Observations from these two missions revealed that the mammalian maternal-offspring system is sensitive to changes in gravity, particularly during the early postnatal period when infants are dependent upon maternal care for their survival. ${ }^{4,9,10}$ For example, Maese and Ostrach report young infant rats experienced mortality and feeding difficulties during these missions. ${ }^{9}$ Further observations revealed that the habitat design played a crucial role in the survival of the youngest neonates. ${ }^{9,10}$ Recent ground based simulated microgravity studies conducted using a clinostat show a reduced birth rate in female mice that were implanted with healthy microgravity-fertilized and cultured embryos as compared to the Earth gravity control group. ${ }^{11}$

Current ISS research includes the Micro-10 investigation (P.I. Tash), which is the first in-vitro study of mammalian sperm in microgravity that compares to Earth-based human in vitro clinical and research tests. The Space Pups experiment (P.I. Wakayamam) is used to study the effects of space radiation on mammalian reproduction by storing freeze-dried mouse sperm aboard the ISS for up to two years, and then using the sperm to fertilize mouse eggs on Earth to produce mouse pups. Recently, Rodent Research-1 demonstrated specific hardware capability to support rodent research for long duration experiments aboard the ISS (NASA Rodents, 2013)

High-level science requirements for a planned long term habitat to support mammalian reproduction and 
development aboard the ISS are discussed and summarized in the proceedings of the ISS Rodent Mark III Habitat (hereafter Mark III) workshop. ${ }^{4}$ The participants of this workshop recommend multigenerational studies to understand mammalian reproduction and maturation in multiple gravity environments, and established a "Roadmap to Multigenerational Studies" in which a plan is described to achieve a full mammalian life cycle in microgravity starting with breeding, birth through weaning, and postnatal development to adulthood. ${ }^{4}$ The aforementioned Rodent Research-1 experiment is the first step to the implementation of the Roadmap.

Research conducted on the reproductive challenges mammals may encounter in partial gravity environments is the next step toward a comprehensive understanding of the mammalian life cycle in multiple gravity environments. This research needs to be carried out prior to the late 2020's in order to inform design decisions on future human Mars missions when systems for these missions are evaluated and planned. Future planning efforts, such as the EMC architecture study, identify capabilities that must be tested in the near-term in order to enable human exploration missions that are beyond the challenges associated with partial gravity reproduction. The Multigenerational Independent Colony for Extraterrestrial Habitation, Autonomy, and Behavior health (MICEHAB) is a conceptual, long duration, autonomous habitat designed to house rodents in a partial gravity environment with the goal of understanding 1 ) the effects of partial gravity on mammalian reproduction and maturation over multiple generations, and 2) how to effectively design such a facility to operate autonomously to support life in remote, partial gravity environments. MICEHAB provides an opportunity to prove out human exploration class hardware and demonstrate capabilities required for autonomous and robotic mission operations prior to human Mars missions, and such a facility is capable of being delivered in the late 2020's. The habitat design considerations are of crucial importance to maintain a long duration facility that allows for the rodent colony to achieve multiple, successful and diverse generations. Therefore, the MICEHAB design follows the recommendations laid out in the "Roadmap to Multigenerational Studies" from the Mark III workshop. ${ }^{4}$

Current long duration mammalian reproduction studies aboard the ISS are tended by crew members and only studies specific milestones associated with the mammalian life cycle. Plans to study full mammalian life cycle in microgravity have been developed ${ }^{4}$ but has yet to be implemented. MICEHAB is unique in that it addresses the combined effects of long duration, partial gravity, and autonomous and robotic operations of systems that feed forward to human-scale systems. The MICEHAB concept is not a replacement for the current planned research paradigm of microgravity rodent studies, but it represents an opportunity to gather biological and systems data in a relevant environment applicable to future settlements on Mars. This paper presents the MICEHAB conceptual design beginning with driving considerations used to formulate the architectural trade space and concept definition in Section II, followed by a detailed description of the chosen baseline spacecraft design in Section III. Included in Section III is a discussion of the MICEHAB capabilities that enable human exploration missions to Mars. The model created for demonstration purposes is described in Section IV, and Section V concludes the paper with a summary and planned future work.

\section{Architectural Trade Space and Concept Definition}

\section{A. Driving considerations}

Mission and facility driving considerations were established in order to limit the applicable mission design space and identify the functionality of the MICEHAB facility, which is both an animal habitat and a space vehicle. The following combination of biological and spacecraft driving considerations are imposed to study multigenerational mammalian reproduction and maturation in partial gravity, and to do so with autonomous and robotic systems.

- The facility must carry all of the required observation and autonomous care equipment to support a relatively large animal colony in a partial gravity environment.

- Telerobotic operations may be required to achieve desired medical and science data.

- The facility design must attempt to isolate the effects of partial gravity from other environmental factors such as habitat design, radiation, and other rodent colony stressors.

- C57BL/6J mice are selected as the preferred species because they are are good breeders, long-lived, have a low susceptibility to tumors, ${ }^{12}$ and flew on the recent Bion-M 1 biosatellite, ${ }^{13}$ as well as in previous Space Shuttle experiments. ${ }^{14,15,16}$

- A minimum of six breeding females per generation is required for statistical significance, as the breeding 
female is the unit of statistical analysis for the study.

- Experiments are required to last through at least three generations: the Earth-born F0 generation comprised of proven adult breeders; the F1 generation born to the F0 generation in a partial gravity environment; and the fully space developed F2 generation born to the F1 generation. ${ }^{4}$

- A generation is approximately 90 days and is defined as the time from conception to when a C57BL/6J should mate. ${ }^{17}$ Three generations of experiments defines a minimum mission duration of about 300 days.

- Data-specific life cycle progression is required to confirm successive milestones of mating, fertilization, birth, weaning, and maturation.

- Microgravity, partial gravity, and full gravity test analogs are required to ensure that partial gravity effects can be isolated, while drawing on results of prior and future microgravity experiments.

- Routine animal observation by a veterinarian and animal health and well-being must be ensured following protocol detailed in the NASA Ames Research Center's Rodent Habitat Project Science Requirements Document ${ }^{18}$ and the Guide for the Care and Use of Laboratory Animals. ${ }^{19}$

- Earth return of deceased animals and return of live animals for acclimation to a full gravity environment are important to research of space biology reproduction and development, therefore, the MICEHAB mission design strategy requires sample return following the protocol set forth in current and future ISS studies. ${ }^{4}$

\section{B. Morphological Matrices}

The preceding list of driving considerations are used to define mission functions, which are then arranged into a morphological matrix to formulate potential mission and vehicle design concepts. The mission and vehicle design space can be visualized through the following three morphological matrices (Tables 1 to 3 ), in which various options are selected (highlighted) to define conceptual mission strategies.

Table 1. Mission Strategy 1 - Balanced feasibility/Earth independence, with moderate in-situ science

\begin{tabular}{|c|c|c|c|c|c|}
\hline Location & Earth-based & ISS or ISS Vicinity & Cis-lunar & $\begin{array}{l}\text { Lunar } \\
\text { surface }\end{array}$ & \\
\hline $\begin{array}{l}\text { Sample } \\
\text { Return }\end{array}$ & None, in-situ analysis & $\begin{array}{l}\text { Autonomous transfer } \\
\text { of samples to ISS or } \\
\text { human habitat }\end{array}$ & $\begin{array}{l}\text { Human } \\
\text { rendezvous and } \\
\text { collection }\end{array}$ & $\begin{array}{l}\text { Specimen } \\
\text { return and } \\
\text { reentry }\end{array}$ & $\begin{array}{l}\text { Facility } \\
\text { return and } \\
\text { entry }\end{array}$ \\
\hline Autonomy & $\begin{array}{l}\text { Earth-independent } \\
\text { with communication } \\
\text { uplink }\end{array}$ & $\begin{array}{l}\text { Earth-controlled } \\
\text { telerobotics }\end{array}$ & & & \\
\hline $\begin{array}{l}\text { Data } \\
\text { collection } \\
\text { level }\end{array}$ & $\begin{array}{l}\text { Simple (blood/urine } \\
\text { samples, physical } \\
\text { exam, visual } \\
\text { observation, } \\
\text { measurements) }\end{array}$ & $\begin{array}{l}\text { Testing for genetic } \\
\text { changes }\end{array}$ & $\begin{array}{l}\text { Dissection/labs } \\
\text { for hormonal } \\
\text { changes/stress }\end{array}$ & $\begin{array}{l}\text { Deceased } \\
\text { rodent } \\
\text { return }\end{array}$ & $\begin{array}{l}\text { Live rodent } \\
\text { return, } \\
\text { Earth } \\
\text { adaptation }\end{array}$ \\
\hline $\begin{array}{l}\text { In-situ data } \\
\text { analysis }\end{array}$ & $\begin{array}{l}\text { Physical exam, } \\
\text { visual, behavioral }\end{array}$ & Vitals, health metrics & $\begin{array}{l}\text { Blood/urine } \\
\text { analysis }\end{array}$ & $\begin{array}{l}\text { Genetic } \\
\text { analysis }\end{array}$ & \\
\hline $\begin{array}{l}\text { Available } \\
\text { launch } \\
\text { platform }\end{array}$ & Hosted payload & $\begin{array}{l}\text { Expendable Launch } \\
\text { Vehicle }\end{array}$ & $\begin{array}{l}\text { SLS primary } \\
\text { cargo }\end{array}$ & $\begin{array}{l}\text { SLS co- } \\
\text { manifested }\end{array}$ & \\
\hline $\begin{array}{l}\text { Spacecraft } \\
\text { vehicle } \\
\text { options }\end{array}$ & $\begin{array}{l}\text { Existing } \\
\text { commercially } \\
\text { available }\end{array}$ & Clean sheet design & $\begin{array}{l}\text { Harvested ISS } \\
\text { element }\end{array}$ & & \\
\hline $\begin{array}{l}\text { Gravity } \\
\text { levels for } \\
\text { testing }\end{array}$ & $\begin{array}{l}\text { Fixed 1/6 Earth's } \\
\text { gravity (Moon) }\end{array}$ & $\begin{array}{l}\text { Fixed 1/3 Earth's } \\
\text { gravity (Mars) }\end{array}$ & $\begin{array}{l}\text { Variable } 1 / 3 \\
\text { and } 1 / 6 \text { Earth's } \\
\text { gravity }\end{array}$ & & \\
\hline
\end{tabular}

\section{Mission Concept Definition}

Each of the three mission strategies (Tables 1 to 3 ) was defined to find the right balance between the desire to maximize science and to demonstrate key autonomy and robotic capabilities. For the purposes of this study, 
Table 2. Mission Strategy 2 - Less extensive science requirements resulting in more Earth independence

\begin{tabular}{|c|c|c|c|c|c|}
\hline Location & Earth-based & ISS or ISS Vicinity & Cis-lunar & $\begin{array}{l}\text { Lunar } \\
\text { surface }\end{array}$ & \\
\hline $\begin{array}{l}\text { Sample } \\
\text { Return }\end{array}$ & None, in-situ analysis & $\begin{array}{l}\text { Autonomous transfer } \\
\text { of samples to ISS or } \\
\text { human habitat }\end{array}$ & $\begin{array}{l}\text { Human } \\
\text { rendezvous and } \\
\text { collection }\end{array}$ & $\begin{array}{l}\text { Specimen } \\
\text { return and } \\
\text { reentry }\end{array}$ & $\begin{array}{l}\text { Facility } \\
\text { return and } \\
\text { entry }\end{array}$ \\
\hline Autonomy & $\begin{array}{l}\text { Earth-independent } \\
\text { with communication } \\
\text { uplink }\end{array}$ & $\begin{array}{l}\text { Earth-controlled } \\
\text { telerobotics }\end{array}$ & & & \\
\hline $\begin{array}{l}\text { Data } \\
\text { collection } \\
\text { level }\end{array}$ & $\begin{array}{l}\text { Simple (blood/urine } \\
\text { samples, physical } \\
\text { exam, visual } \\
\text { observation, } \\
\text { measurements) }\end{array}$ & $\begin{array}{l}\text { Testing for genetic } \\
\text { changes }\end{array}$ & $\begin{array}{l}\text { Dissection/labs } \\
\text { for hormonal } \\
\text { changes/stress }\end{array}$ & $\begin{array}{l}\text { Deceased } \\
\text { rodent } \\
\text { return }\end{array}$ & $\begin{array}{l}\text { Live rodent } \\
\text { return, } \\
\text { Earth } \\
\text { adaptation }\end{array}$ \\
\hline $\begin{array}{l}\text { In-situ data } \\
\text { analysis }\end{array}$ & $\begin{array}{l}\text { Physical exam, } \\
\text { visual, behavioral }\end{array}$ & Vitals, health metrics & $\begin{array}{l}\text { Blood/urine } \\
\text { analysis }\end{array}$ & $\begin{array}{l}\text { Genetic } \\
\text { analysis }\end{array}$ & \\
\hline $\begin{array}{l}\text { Available } \\
\text { launch } \\
\text { platform } \\
\end{array}$ & Hosted payload & $\begin{array}{l}\text { Expendable Launch } \\
\text { Vehicle }\end{array}$ & $\begin{array}{l}\text { SLS primary } \\
\text { cargo }\end{array}$ & $\begin{array}{l}\text { SLS co- } \\
\text { manifested }\end{array}$ & \\
\hline $\begin{array}{l}\text { Spacecraft } \\
\text { vehicle } \\
\text { options }\end{array}$ & $\begin{array}{l}\text { Existing } \\
\text { commercially } \\
\text { available } \\
\end{array}$ & Clean sheet design & $\begin{array}{l}\text { Harvested ISS } \\
\text { element }\end{array}$ & & \\
\hline $\begin{array}{l}\text { Gravity } \\
\text { levels for } \\
\text { testing }\end{array}$ & $\begin{array}{l}\text { Fixed 1/6 Earth's } \\
\text { gravity (Moon) }\end{array}$ & $\begin{array}{l}\text { Fixed 1/3 Earth's } \\
\text { gravity (Mars) }\end{array}$ & $\begin{array}{l}\text { Variable } 1 / 3 \\
\text { and } 1 / 6 \text { Earth's } \\
\text { gravity }\end{array}$ & & \\
\hline
\end{tabular}

Table 3. Mission Strategy 3 - Maximize science investment

\begin{tabular}{|c|c|c|c|c|c|}
\hline Location & Earth-based & ISS or ISS Vicinity & Cis-lunar & $\begin{array}{l}\text { Lunar } \\
\text { surface }\end{array}$ & \\
\hline $\begin{array}{l}\text { Sample } \\
\text { Return }\end{array}$ & None, in-situ analysis & $\begin{array}{l}\text { Autonomous transfer } \\
\text { of samples to ISS or } \\
\text { human habitat }\end{array}$ & $\begin{array}{l}\text { Human } \\
\text { rendezvous and } \\
\text { collection }\end{array}$ & $\begin{array}{l}\text { Specimen } \\
\text { return and } \\
\text { reentry }\end{array}$ & $\begin{array}{l}\text { Facility } \\
\text { return and } \\
\text { entry }\end{array}$ \\
\hline Autonomy & $\begin{array}{l}\text { Earth-independent } \\
\text { with communication } \\
\text { uplink }\end{array}$ & $\begin{array}{l}\text { Earth-controlled } \\
\text { telerobotics }\end{array}$ & & & \\
\hline $\begin{array}{l}\text { Data } \\
\text { collection } \\
\text { level }\end{array}$ & $\begin{array}{l}\text { Simple (blood/urine } \\
\text { samples, physical } \\
\text { exam, visual } \\
\text { observation, } \\
\text { measurements) }\end{array}$ & $\begin{array}{l}\text { Testing for genetic } \\
\text { changes }\end{array}$ & $\begin{array}{l}\text { Dissection/labs } \\
\text { for hormonal } \\
\text { changes/stress }\end{array}$ & $\begin{array}{l}\text { Deceased } \\
\text { rodent } \\
\text { return }\end{array}$ & $\begin{array}{l}\text { Live rodent } \\
\text { return, } \\
\text { Earth } \\
\text { adaptation }\end{array}$ \\
\hline $\begin{array}{l}\text { In-situ data } \\
\text { analysis }\end{array}$ & $\begin{array}{l}\text { Physical exam, } \\
\text { visual, behavioral }\end{array}$ & Vitals, health metrics & $\begin{array}{l}\text { Blood/urine } \\
\text { analysis }\end{array}$ & $\begin{array}{l}\text { Genetic } \\
\text { analysis }\end{array}$ & \\
\hline $\begin{array}{l}\text { Available } \\
\text { launch } \\
\text { platform }\end{array}$ & Hosted payload & $\begin{array}{l}\text { Expendable Launch } \\
\text { Vehicle }\end{array}$ & $\begin{array}{l}\text { SLS primary } \\
\text { cargo }\end{array}$ & $\begin{array}{l}\text { SLS co- } \\
\text { manifested }\end{array}$ & \\
\hline $\begin{array}{l}\text { Spacecraft } \\
\text { vehicle } \\
\text { options }\end{array}$ & $\begin{array}{l}\text { Existing } \\
\text { commercially } \\
\text { available }\end{array}$ & Clean sheet design & $\begin{array}{l}\text { Harvested ISS } \\
\text { element }\end{array}$ & & \\
\hline $\begin{array}{l}\text { Gravity } \\
\text { levels for } \\
\text { testing }\end{array}$ & $\begin{array}{l}\text { Fixed 1/6 Earth's } \\
\text { gravity (Moon) }\end{array}$ & $\begin{array}{l}\text { Fixed } 1 / 3 \text { Earth's } \\
\text { gravity (Mars) }\end{array}$ & $\begin{array}{l}\text { Variable } 1 / 3 \\
\text { and } 1 / 6 \text { Earth's } \\
\text { gravity }\end{array}$ & & \\
\hline
\end{tabular}


Mission Strategy 1 is chosen as the baseline concept design in order to provide the appropriate balance and to allow for more options in the facility design. The conceptual facility artificially produces Mars-like gravity and is located in cis-lunar space for testing in a relevant deep space radiation environment. MICEHAB will launch as a co-manifested payload on a Space Launch System (SLS) with an Exploration Upperstage. The SLS provides the required energy to achieve the desired cis-lunar orbit, and MICEHAB will hitch a ride on an SLS already going to a nearby cis-lunar orbit to deliver a human exploration asset. MICEHAB is a clean sheet habitat design based on a commercial spacecraft that will meet the SLS co-manifested volume and mass restrictions.

Sample return is accomplished through autonomous facility transfer to the nearby pre-placed initial cislunar human habitat. The facility will operate autonomously with respect to a majority of the medical and vehicle functions, however, certain medical procedures will require tele operations. Data collection through blood/urine samples, vital statistics, physical exams, visual observations, and behavioral observations will be performed in-situ, while in-depth genetic testing will be performed on deceased and live samples returned to Earth. Most of the data will be uplinked and downlinked to Earth during a scheduled ground pass; however, the facility will also have a near real-time (less than 2 seconds delay) communication capability used for video feeds and telerobotic medical procedures. Section III describes in detail the baseline MICEHAB vehicle and habitat design based on Mission Concept 1.

\section{Baseline Spacecraft Design}

\section{A. Overview and Assumptions}

\section{A.1. Spacecraft Concept of Operation}
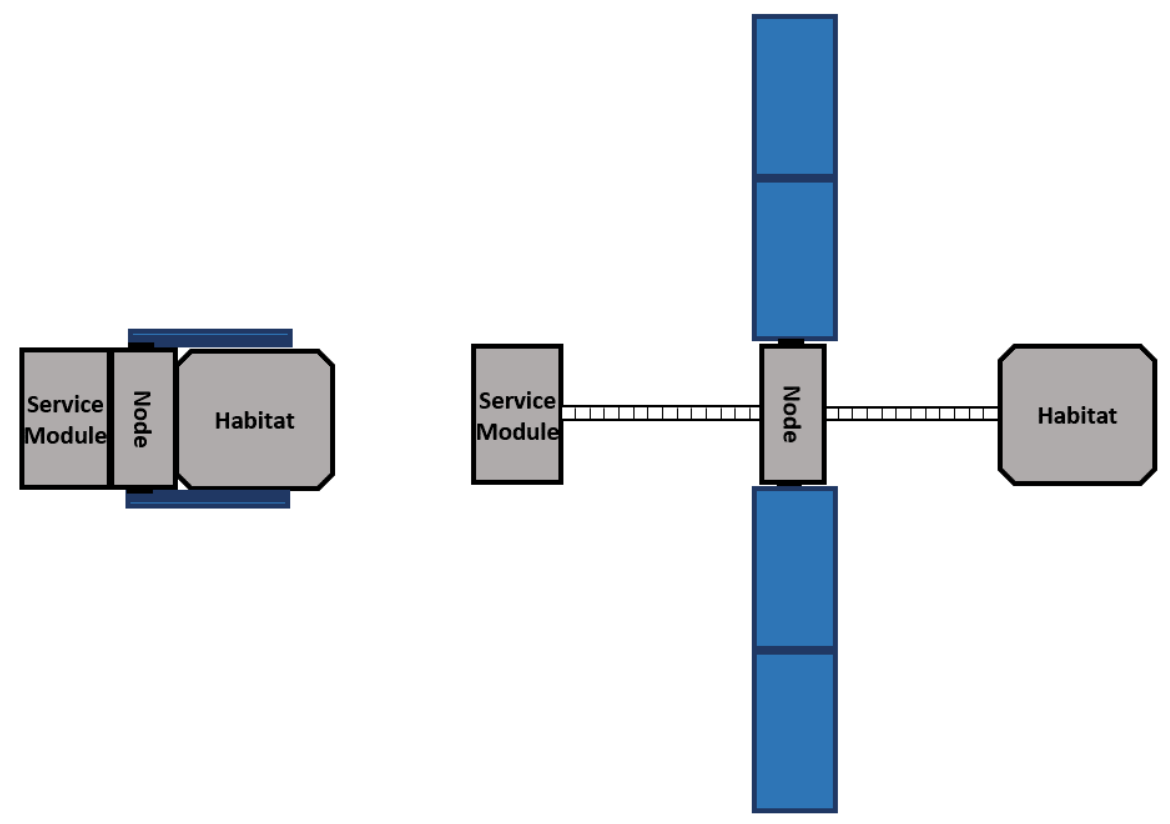

Figure 1. MICEHAB vehicle configuration: [left] packaged for launch and [right] deployed.

MICEHAB is designed to support a long duration mission in a partial gravity environment analogous to planetary destinations. The facility will nominally launch as a co-manifested payload on an SLS to a lunar distant retrograde orbit (LDRO) where the service module portion of the vehicle will insert the spacecraft into the desired orbit. The facility will then deploy using a tether system attached to the service module at one end, and the habitat at the other end as shown in Figure 1. Solar array panels are attached to a node located at the center of mass. The entire facility will spin up about the center of mass using Reaction Control System (RCS) attached to the service module and the habitat spacecraft. The rotation will induce a Mars-like partial gravity $(\approx 1 / 3$ Earth gravity) with spin rate analogous to acceptable limits for humans. 
Every year the facility will spin down and the tether will retract both the habitat and the service module back toward the center of mass. The facility will then transfer to the planned EMC cis-lunar habitat and dock, and one of the MICEHAB robots will transfer samples to the Caretaker robot aboard the human habitat. The yearly rendezvous with the cis-lunar habitat will coincide with planned human missions in order for the MICEHAB samples to be loaded onto the Orion capsule for Earth return with the crew and for maintenance on the MCIEHAB if required. Logistics for habitat maintenance or animal care will be transferred from the human habitat to the MICEHAB during this time.

The MICEHAB facility will then undock and return to its orbit location, which trails the human habitat. It is assumed transfer time to and from the human habitat will last a few days or possibly up to one week. The actual transfer time will depend on the keep out zone designated for the human habitat. The orbit phasing will be selected to ensure the shortest travel time from the MICEHAB orbit location to the human habitat. Once back to its original location, the MICEHAB facility will redeploy and resume its rotation and partial gravity operations. The yearly transfer to the initial cis-lunar habitat will continue for 10 years.

A communications asset will launch attached to the facility and will be inserted in the same orbit to trail the MICEHAB. The facility will spin with its solar panels continuously facing the sun to generate the power required to keep the habitat operational. The communications antenna attached to the habitat will point toward the communication assets, which acts as a communication relay for the habitat. Maximizing the communication capability of the MICEHAB is critical to its science mission.

\section{A.2. Animal Habitat}

While the facility is rotating to simulate partial gravity, observations of the mice will be ongoing inside of the animal habitat. Isolation and population control are the guiding principles within the habitat and drive the design and structure of the animal enclosures. Adult male mice may participate in aggression towards one another or may cannibalize the litter, ${ }^{12,13,20}$ and sometimes female mice will engage in barbering when in the presence of male mice. These behaviors are mitigated by the isolation policy because one mouse is assigned to one enclosure. The mice are arranged in mating trios, where a male mouse is housed between two female mice, and tunnels are installed between each enclosure so that the mice can mate during specified mating times. The male and female mice are separated after mating so that the female can birth and wean the litter. Post weaning, the pups are removed robotically from the enclosure and then physically examined by a medical robot. Some pups are electronically tagged and then placed in a new enclosure. These pups will mature to adults and then be allowed to mate within in a mating trio. Other pups are euthanized, dissected, and then stored in a medical freezer for return back to Earth. Euthanizing controls the population because the habitat spacecraft is a defined size and shape, and a mass limit is imposed in order for the facility to be successfully launched to the desired LDRO. A minimum of six female mice per generation are required for statistical significance, however, MICEHAB will strive to maintain 10 females per generation through a population control strategy described in the Population Control section (H.1).

\section{B. Trajectory Options and Selection}

The primary target orbit for MICEHAB is a LDRO, which will be the same orbit as the planned initial cis-lunar human habitat. The exact orbit for this habitat has yet to be defined, but an LDRO type orbit is generally agreed as the likely destination. The LDRO is a very stable orbit around the Moon that provides MICEHAB an opportunity to conduct experiments outside the Earth's magnetosphere, simulating longterm deep space exploration while keeping the cost of orbital maintenance to a minimum. There are several options for transfer from Earth to LDRO, and the cost of the transfer is generally inversely proportional to the transit time.

Three types of trajectories were considered for MICEHAB transit to LDRO. To minimize the propulsive requirement for MICEHAB, the trajectories all begin with a launch vehicle injection to a characteristic energy (C3) of at least $-2 \mathrm{~km}^{2} / \mathrm{s}^{2}$. The shortest of these transits is a direct far-side insertion to LDRO shown in Figure 2. The trajectory requires the launch vehicle to deliver the payload to a C3 of $-1.62 \mathrm{~km}^{2} / \mathrm{s}^{2}$ with a perigee altitude of $200 \mathrm{~km}$. From there, MICEHAB takes roughly 7 days to travel to the far-side of the moon near the Earth-Moon L2 point and does a $560 \mathrm{~m} / \mathrm{s}$ propulsive insertion into the LDRO. This fast transit is extremely costly, as it requires the launch vehicle to deliver the payload to beyond lunar distant and requires a large propulsive maneuver for insertion. The combination of the higher injection energy and large maneuver could limit the MICEHAB mass to an unreasonable level which would limit the usefulness 


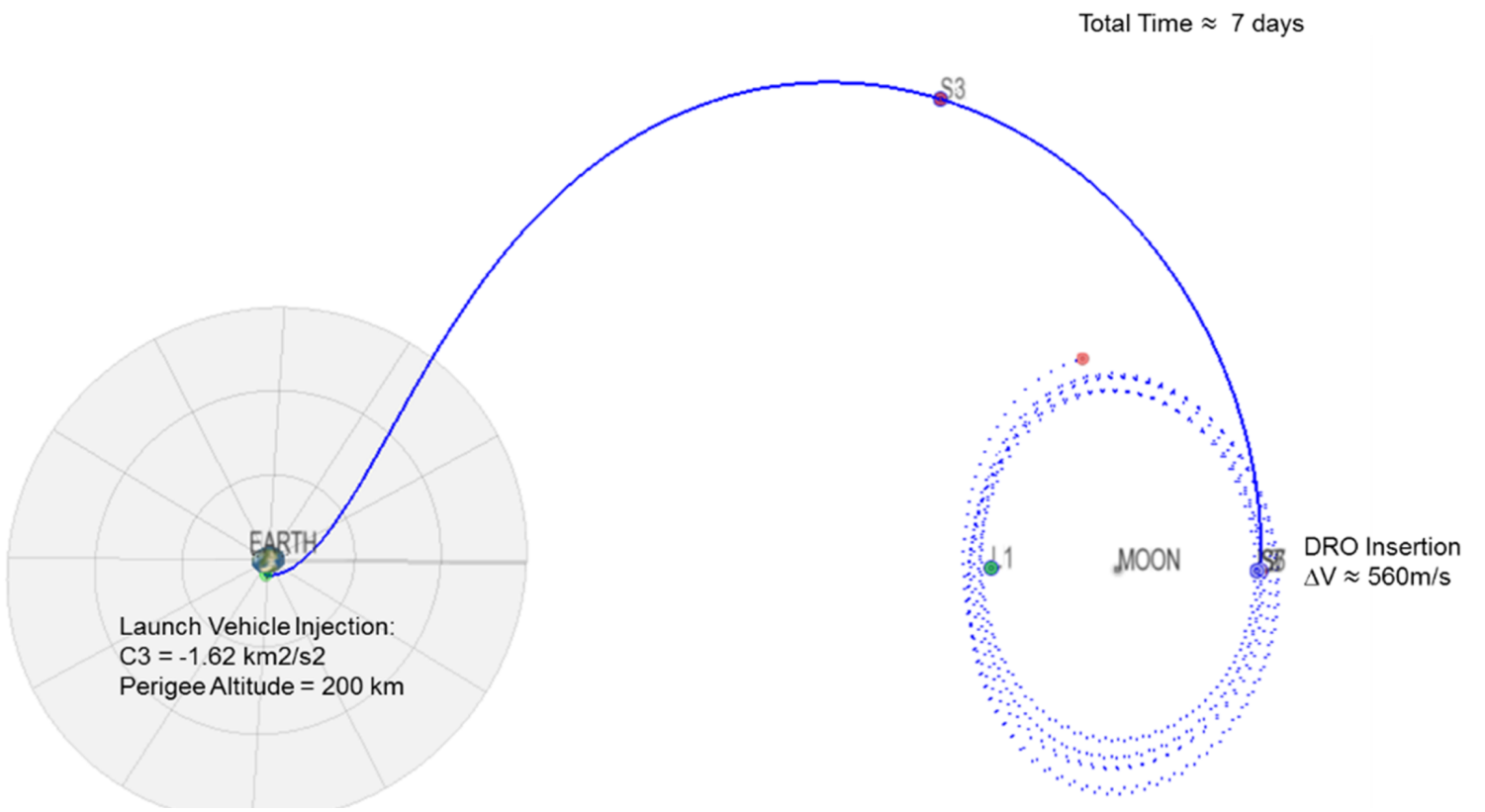

Figure 2. Example Direct Far-side Insertion to Lunar Distant Retrograde Orbit

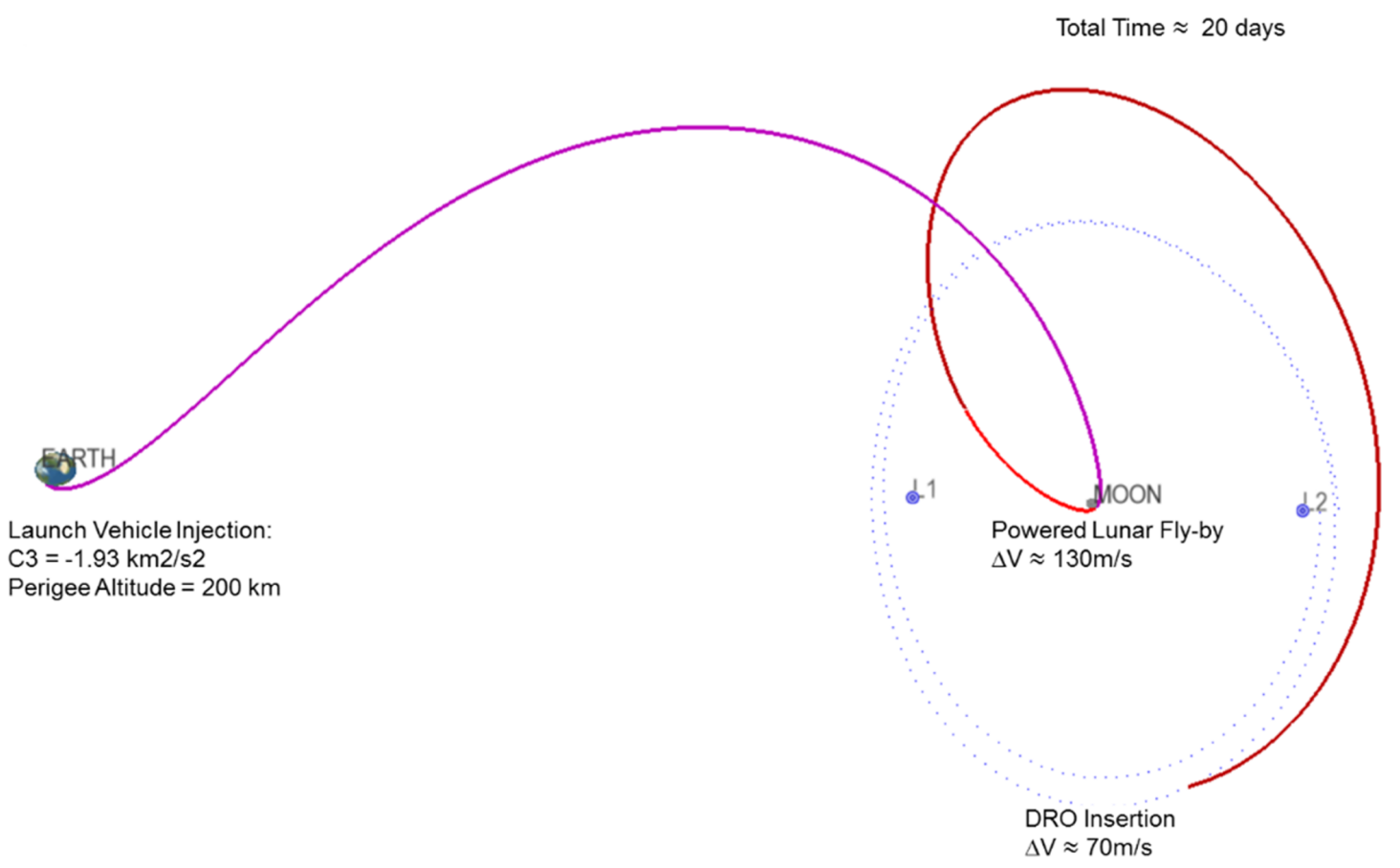

Figure 3. Example Powered Lunar Flyby Insertion to Lunar Distant Retrograde Orbit 
of the experiment through the reduced duration, number of subjects, and functionality. However, the fast transit can be beneficial to the experiment as it requires the animals to spend less time in microgravity before the start of the experiment.

The second type of trajectory utilizes a powered lunar flyby to reduce the propulsive requirement for insertion into LDRO. This trajectory is shown in Figure 3. For this trajectory, the launch vehicle injection C3 is reduced to $-1.93 \mathrm{~km}^{2} / \mathrm{s}^{2}$, which increases the payload delivery capability of the launch vehicle. From injection, the spacecraft travels 6 days and targets a lunar flyby. During the flyby, the spacecraft performs a propulsive maneuver of $130 \mathrm{~m} / \mathrm{s}$ to boost change its trajectory for a LDRO insertion 8 days later with a second maneuver of around $70 \mathrm{~m} / \mathrm{s}$. In total, compared to the direct far-side injection, the flyby maneuver reduces the launch vehicle C3 by $20 \%$ and reduces the total propulsive maneuver cost by more than $60 \%$. However, this maneuver triples the transit time to more than 20 days, meaning that the animals will spend longer in microgravity prior to the start of the experiment.

The third and final trajectory (not illulstrated) considered for MICEHAB is a minimum energy trajectory that utilizes two lunar gravity assists and solar perturbation to insert into LDRO. The trajectory begins with a launch vehicle injection C3 of $-2 \mathrm{~km}^{2} / \mathrm{s}^{2}$ and targets an unpowered lunar gravity assist. This gravity assist maneuver takes the spacecraft near the edge of the Earth-Moon sphere of influence. Here, the spacecraft performs a $70-80 \mathrm{~m} / \mathrm{s}$ maneuver to target a second lunar gravity assist. The second lunar gravity assist helps reorient the spacecraft so that it falls into the LDRO without further propulsive requirement. In total, this trajectory costs less than $100 \mathrm{~m} / \mathrm{s}$ of propulsive maneuver, which is a $80 \%$ reduction compared to the direct insertion and a $50 \%$ reduction compared to the powered lunar flyby trajectory. However, the total transit time for this trajectory is on the order of 6-7 months, which is significantly more than the other two trajectories considered.

MICEHAB will use the second trajectory option (Figure 2) with a powered lunar flyby, for arrival at the LDRO approximately 20 days after launch because this option increases the payload delivery capability of the launch vehicle and reduces the propulsive requirement for insertion into LDRO. The powered lunar flyby option also provides more flexibility in the design of the habitat and supporting assets.

\section{Service Module}

Assuming a 10 metric ton (mT) SLS co-manifested cargo capacity on a trajectory to LDRO, the insertion burns will be performed by a commercially available service module augmented with additional propellant. To help minimize the system complexity of the service module, storable propellants are chosen instead of cryogenic propellants. The service module will serve as the counter mass of the MICEHAB after the completion of its primary propulsive maneuvers, so a balance between minimizing the mass for the propulsive maneuvers and optimizing the counter mass for the tether system must be achieved. The RCS on the service module will be utilized in conjunction with the system on the habitat for the spin-up/spin-down maneuvers that are required to generate the artificial gravity. The service module is assumed to be appropriately $2 \mathrm{mT}$ based on the estimate of $7 \mathrm{mT}$ for the habitat, $1.5 \mathrm{mT}$ for the communications waypoint, and the desired tether length distance that produces two Rotations Per Minute (RPM) for the rotation of the facility. Initial analysis indicates that this combination of element masses will be feasible for the $10 \mathrm{mT}$ mass at LDRO injection, and ongoing analyses will adjust the facility design to meet this mass constraint as system designs are refined. The service module propellant will be used each time the facility transfers to and from the initial cis-lunar human habitat and possibly to counteract a RCS burn used to spin-up and spin-down the facility. Approximately $50 \mathrm{~m} / \mathrm{s}$ is required of the RCS for every spin-down and spin-up maneuver, during which the thrusting vector needs to be balanced to maintain stability in the LDRO. If there is disruption to the stability of the orbit, then a small burn of the service module may be required.

\section{Facility Rotation}

To enable partial gravity environments for the MICEHAB facility, the overall system architectural design envisioned is the habitat facility and a counter mass rotating about a common axis such that the rodents experience an artificial gravity environment similar to Mars gravity. The counter mass and habitat have a deployable structural connection (e.g. boom, tether, etc.) that keeps the facility in a fixed rotational plane (akin to a "dumbbell" configuration) and also serves as a signal conduit for subsystems, such as power, guidance, navigation, and communications. At the center of the axis of rotation is either a stationary or similarly rotating core node housing the solar arrays. Two options are considered for the orientation of solar 
panels; 1) one in which the MICEHAB solar panels are always pointing at the sun, and 2) one in which the solar panels are rotating with the rest of the facility and are sized in order to achieve enough solar irradiance incident upon the solar panels for the power requirements (Please refer to the Power section G for a complete discussion).

A consideration for the physiological impacts of the facility rotation is the Coriolis effect, which is caused by a "fictional force" due to movement viewed in a rotating frame, and it causes an apparent acceleration on the moving object. If this object is a living being (human or rodent), it can cause nausea, dizziness, and disorientation. ${ }^{21}$ Previous studies on the acceptable limits for comfort for humans show that habitats with large radii and lower angular velocity to achieve desired centripetal acceleration are ideal for habitability and comfort. Unfortunately, spacecraft are constrained by mass and volume and make achieving these dimensions challenging. Significant research has been done on the effects of centrifuge radii and velocity on comfort for human crew, and they indicate that humans can become adapted to Coriolis-induced nausea. Several authors have agreed on a "comfort zone" for humans, and from those studies, to achieve a minimum artificial gravity environment of approximately $0.38 \mathrm{~g}$, a minimum radius of rotation required is $85.0 \mathrm{~m}$ with a maximum angular velocity of approximately $2.0 \mathrm{RPM} .{ }^{22}$

In addition to the disorientation effect from Coriolis acceleration, gravity gradient can also be an issue for habitability in habitat in radial orientation. If the MICEHAB facility will rotate with a radial orientation, the gravity gradient constraints are to not exceed a 5.0\% change in the gravitational acceleration across the length of the habitat facility. As an example calculation, assuming a $3 \mathrm{~m}$ tall habitat facility based on commercial cargo spacecraft, ${ }^{23}$ this corresponds to a radius of rotation of greater than $60.0 \mathrm{~m}$. For rodent-specific rotating habitat designs, the Coriolis effects are related to the size, translation speed, and habitat architecture, and some studies have investigated the effects of rotation on rodent "comfort". ${ }^{24}$ As the purpose of the MICEHAB concept is to inform future crew health and performance of human habitat designs and missions, the baseline MICEHAB design follows the current limits and comfort zone for humans.

\section{E. Tether System}

Two preliminary concepts were investigated from previous studies in the literature ${ }^{25,26}$ for the deployable structural member connecting the habitat facility and the counter mass in the MICEHAB design: flexible, rope-like tethers and rigidizable booms. A trade study for the boom and tether concepts is underway and includes material parameters such as the lateral bending stiffness, torsional stiffness, lineal density (mass), tensile strength, as well as the complexity of packaging, deployment, and retraction mechanisms. In general, a flexible tether can only apply tension forces, cannot constrain the system in one dimension, and requires more complex propulsion and control. Rigidizable booms in general have greater lineal density and stiffness parameters than flexible tethers.

In addition to the requirement of the deployable structural member to package compactly and deploy reliable into a stable geometry as part of the concept of operations of the MICEHAB system, primary considerations for the design are the structural loads and physical dimensions of the structural member required to achieve the desired baseline parameters for the facility rotation. From the discussions in the Facility Rotation section, assuming a radius of rotation of $85.0 \mathrm{~m}$ (to stay within the comfort zone and adhere to the constraints for the gravity gradient across the habitat), an angular rate of $2.0 \mathrm{RPM}$ (to achieve an artificial gravity environment of approximately $0.38 \mathrm{~g}$ ), and a mass of $5,000 \mathrm{~kg}$ for the habitat facility (based on preliminary habitat sizing and analysis of commercial cargo spacecraft), the tension on the structural member is approxi-

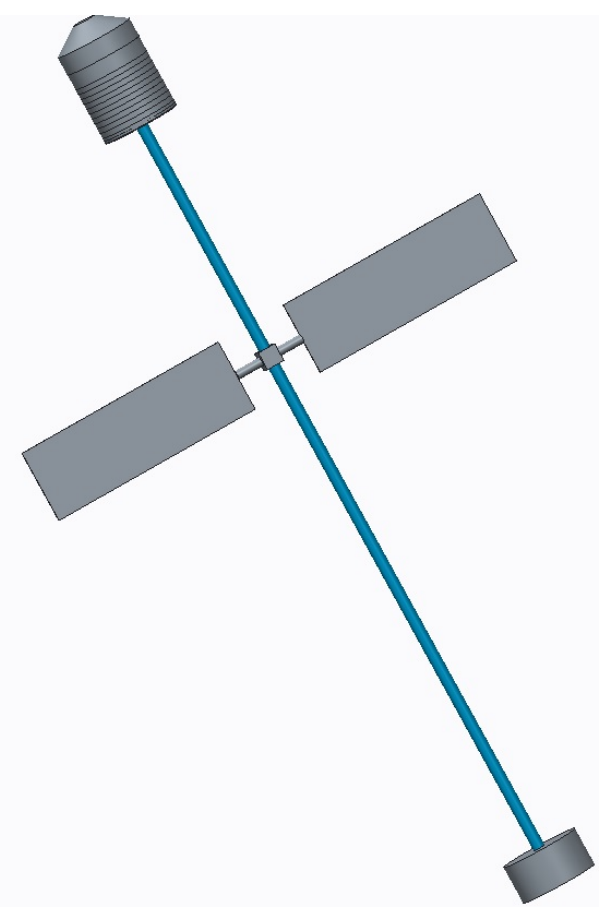

Figure 4. MICEHAB facility including habitat [top left], solar panels [middle], and service module as counter balance [bottom right]. Tethers are 1/10 the actual length, while the rest of the elements are to scale mately $20.0 \mathrm{kN}$.

In previous reports, flexible tethers were proposed for several cis-lunar space transportation system 
architectures, and those reports indicate that the flexible tethers can be scaled to the baseline load and length values aforementioned. ${ }^{27,28,29}$ An orbital winch mechanism has been designed for controlled deployment and retraction. Similarly, a coilable, rigidizable boom concept has been developed and been successfully launched and deployed in solar sail systems and other spacecraft payloads. ${ }^{30,31}$ For the coilable boom, the boom components are stowed in a canister package and can be extended and retracted via a lanyard and motor drive system. Whereas the previous, successful deployments were with boom lengths on the order of $10 \mathrm{~m}$, preliminary calculations indicate that the deployable boom can be scaled for the baseline loads and greater lengths for the MICEHAB structural member.

The MICEHAB system has a pre-deployment, packaged configuration (Figure 1 [left]) in which the habitat facility and counter mass (service module) are connected to the core node (to which the solar panels are attached) between them. The solar arrays are packaged length wise along the side of the counter mass and the habitat facility. Also, in the packaged configuration, the structural member (e.g., a flexible tether or rigidizable boom) is initially retracted in a stowed state, apportioned to the counter mass, core node, or habitat facility in a separate canister.

In the concept of operations, once the vehicle reaches the desired orbit in LDRO, the solar panels are deployed perpendicular to the facility and counter mass, and the MICEHAB system would initiate a very slow rotation while the facility, core node, and counter mass are still joined. Subsequently, the habitat facility and counter mass would separate slowly from the core structure via controlled extension of the structural member. To increase the rotation while deploying, low-thrust RCS on both ends of the facility, controlled by feedback would insure that the rodents experience gradual changes in accelerations and control any induced dynamics as well. After the full extension of the structural member and the complete spin-up to the desired angular velocity for the habitat's partial gravity environment, the core mode is at the position of the center of mass of the system (which is also the axis of rotation). In this completely deployed configuration, the habitat facility and counter mass, constrained to a rotational plane via the structural member, revolve about the axis of rotation. Figure 4 shows the deployed MICEHAB facility where the tether lengths are scaled to $1 / 10$ of their actual length.

During MICEHAB rendezvous with the cis-lunar human habitat, the solar arrays stay deployed while the facility de-spins. The structural member partially retracts to a length such that a structural truss or other connection mechanism can be latched or engaged to enable a rigid, stable physical connection between the core node, counter mass, and habitat facility for controlled navigation of the MICEHAB during rendezvous.

\section{F. Communications}

The communication and navigation system aboard the MICEHAB spacecraft will be an integral aspect of the design for creating an autonomous partial gravity environment. The communication architecture must be able to both receive command uplink and effectively point at the Earth for data downlink, without impeding the spacecraft's continuous rotation. The current concept is to utilize a waypoint to receive transmissions from the spacecraft and to pass the information onward to Earth. Due to the spacecraft's continuous rotation, accurately pointing at the Earth from a LDRO is a difficult exercise and one which can introduce inaccuracies into the system. Pointing to a much closer target of a relay satellite and allowing the relay satellite to then accurately point to the Earth is a much more practical option. The spacecraft antenna will be located along the axis of the craft's rotation in order to provide a continuous communication link to the relay satellite.

The MICEHAB spacecraft will also be outfitted with an antenna capable of receiving uplink directly from Earth. Since ground stations are relatively independent of sizing and power restrictions aboard interplanetary communication systems, the uplink signal will be powerful enough to bypass the waypoint relay and reach the spacecraft directly. Sending uplink directly to the spacecraft is common practice in order to send and receive emergency commands with a higher fidelity. The waypoint relay will be available to act as an auxiliary system for signal uplink if the Earth is unable to effectively contact the spacecraft for a variety of reasons. An assumption in providing the waypoint as an auxiliary system is that the waypoint is able to track both the spacecraft and the Earth.

The waypoint will be equipped with a reception antenna pointed toward the MICEHAB and a transmission antenna focused on Earth. Additionally, the current design is for the MICEHAB to be equipped with at least 600 cameras for surveying the mice during orbit. The assumption made to deliver a telemetry data rate of 26 megabits per second is that only three high definition and two standard definition cameras will be operating simultaneously at any given time. The rest of the camera data will be compressed with a lossy method and then sent via downlink. The current concept has all processing occur first aboard the spacecraft 
allowing the waypoint to act only as a bent-pipe relay.

The design of the communication architecture begins by specifying a frequency that would be capable of transmitting signals to Earth from the MICEHAB orbit. An Ka-Band frequency of $31.4 \mathrm{GHz}$ and an S-Band frequency of $7.19 \mathrm{GHz}$ are suitable for downlink and uplink operations, respectively. Since the waypoint receives and relays the same signal from the spacecraft, both the receiving and transmitting frequencies are $31.4 \mathrm{GHz}$. Following standard practice for designing a reliable communication system, the link margin must be at least $3 d B$, and in most situations closer to $10 d B$. Each onboard communication system is expected to provide $25 \mathrm{~W}$ of power for transmitting data. With the frequency and power parameters decided, the diameters of each antenna are evaluated to provide a fitting link margin at a minimal mass. The final simulated antenna sizes for the MICEHAB spacecraft are a $0.3 \mathrm{~m}$ antenna transmitting to earth, a $0.05 \mathrm{~m}$ antenna for receiving from Earth, and a $0.3 \mathrm{~m}$ antenna for transmitting to the waypoint.

The waypoint satellite is outfitted with two $0.3 \mathrm{~m}$ antennas, one for transmitting to Earth and one for receiving from the MICEHAB spacecraft. The ground stations used as targets for communications are Goldstone, Madrid, and Canberra. Each of these ground stations has a $70 \mathrm{~m}$ dish antenna operating within Ka-Band frequencies. The previously described architecture results in an uplink margin from Earth to the spacecraft of $64 d B$. The downlink margin from the spacecraft to the waypoint is $15 d B$ and the downlink margin from the waypoint to Earth is $17.7 \mathrm{~dB}$. As discussed previously, the uplink margin is much higher than the required link margin because the ground stations are capable of transmitting such a powerful signal. Therefore, a small receiving antenna is capable of minimizing satellite mass while maintaining a large link margin. The two downlink margins are also slightly larger than the required $3 d B$ in order to ensure that unexpected inefficiencies do not cause the system to fail. Utilizing the described architecture will result in a communication system aboard the MICEHAB spacecraft that will reliably return scientific data from a LDRO with the goal of creating an autonomous partial gravity environment.

To determine the communication array to be placed aboard the MICEHAB, various communication architectures are analyzed utilizing the SPAcecraft SIMulator (SPASIM) ${ }^{32}$ software. SPASIM simulates the functions and resources of a spacecraft to quickly perform conceptual design (Phase A) trades and sensitivity analyses and uncover operational bottlenecks during any part of the mission. ${ }^{31}$ The frequency of operation, the antenna dish diameter, and the provided transmission power are all systematically incremented to derive an optimized solution. The first stage includes rotating between Ka-Band and X-Band (at an equivalent antenna diameter and nominal power) to establish a relationship between the two frequencies of operation. The transmissions are first tested with a $70 \mathrm{~m}$ ground station antenna. The large link margin indicates that the size of the ground station could be reduced to a $34 \mathrm{~m}$ antenna within the X-Band frequencies. The Ka-Band does not have the option for utilizing a smaller antenna so all of the calculations are performed on a $70 \mathrm{~m}$ ground station antenna. In general, using the Ka-Band results in a link margin about $10 \mathrm{~dB}$ higher for transmissions arriving or leaving the Earth.

Table 4. The table below depicts the diameters of the antennas on both the spacecraft (S/C) and waypoint (WP) within both the X-Band and Ka-Band frequencies.

\begin{tabular}{lcc} 
& X-Band & Ka-Band \\
\hline Operating Frequency $(G H z)$ & 8.45 & 31.4 \\
S/C transmitting to Earth Antenna $(m)$ & 0.3 & 0.15 \\
S/C receiving from Earth Antenna $(m)$ & 0.05 & 0.05 \\
WP transmitting to Earth Antenna $(m)$ & 0.3 & 0.05 \\
WP receiving from S/C Antenna $(m)$ & 0.3 & 0.25 \\
Ground Station Antenna $(m)$ & 34 & 70 \\
\hline
\end{tabular}

Continuing the analysis indicates that a $0.3 \mathrm{~m}$ diameter dish is acceptable for spacecraft to waypoint transmissions in both the X-Band and the Ka-Band. Beyond inter-satellite transmissions, the Ka-Band is capable of transmitting a signal at the same link margin from a smaller antenna diameter. Possible geometries of the antennas aboard both the waypoint and the spacecraft for both frequencies are summarized in Table 4. The Ka-Band allows for smaller antenna diameters to be installed for every communication phase except for inter-satellite downlink. The resulting mass savings from employing the Ka-Band could expected to be about $4 \mathrm{~kg} \cdot{ }^{33}$ However, beyond the positive mass savings, there are negative aspects for designing a system to utilize the higher frequency Ka-Band. The first negative aspect is that the cost of utilizing the $70 \mathrm{~m}$ Ka-Band ground station is much higher. The cost of a single large antenna increases with the diameter as 
$d^{2.7}$, where $\mathrm{d}$ is antenna diameter. ${ }^{34}$ Beyond construction costs, larger antennas require much more intensive maintenance and calibration. Therefore, utilizing an X-Band connection to a $34 \mathrm{~m}$ ground station instead would result in savings of approximately $\$ 82,000 .{ }^{34}$

The second fault with using a Ka-Band frequency is that receiving a frequency allocation above $25 \mathrm{GHz}$ from the International Telecommunications Union (ITU) can be difficult, especially when considering lunar missions. The ITU gives special consideration to radio astronomy investigations into atmospheric composition at frequencies above $25 \mathrm{GHz}$. The increasing attenuation by neutral atmospheric gasses makes performing such measurements difficult from the Earth, even at optimal ground station locations. ${ }^{35}$ In comparison the lack of atmosphere and dry conditions makes lunar orbit ideal for such astronomical observations. Despite the difficulties associated with employing a Ka-Band system, the higher frequency architecture provides a much larger telemetry data rate for data downlink. Therefore the Ka-Band can support the massive data generation that is continuously occurring onboard the MICEHAB. At such high telemetry rates the link margin of the X-Band system rapidly deteriorates and is no longer a suitable connection. In order to ensure that the communication system will create a reliable communication link between all components if the MICEHAB mission, the Ka-Band frequency of $31.4 \mathrm{GHz}$ is selected as the primary operating frequency for the downlink transmissions.

\section{G. Power}

The preliminary power system is designed based on the cumulative energy requirements of the service module and the mice habitat aboard the spacecraft. Utilizing solar panels allows for the design to avoid the complications of designing a habitat shielded from a nuclear core. After analyzing several solar panel geometries, a final assembly of two fixed solar panels perpendicular to the spacecraft's axis of rotation is determined to be optimal. Using two $18 \mathrm{~m}^{2}$ gallium arsenide solar panels provides the required $7 \mathrm{~kW}$ end of life power to the vehicle. The corresponding mass of the solar panel array is determined to be approximately $430 \mathrm{~kg}$, with a specific power of 0.04 kilograms per watt. $^{36}$

Using SPASIM allowed for a variety of solar panel geometries and panel compositions to be analyzed quickly. The main design consideration is to select a geometry which maximized the amount of incident solar flux on the panels without compromising the spacecraft's continual rotation. A solar flux of $1367.6 \mathrm{~W} / \mathrm{m}^{2}$ is considered to be an accurate average value for calculating power output. Included alongside the solar flux assumption, is the assumption that an annual solar cell degradation of $4 \%$ could be expected.
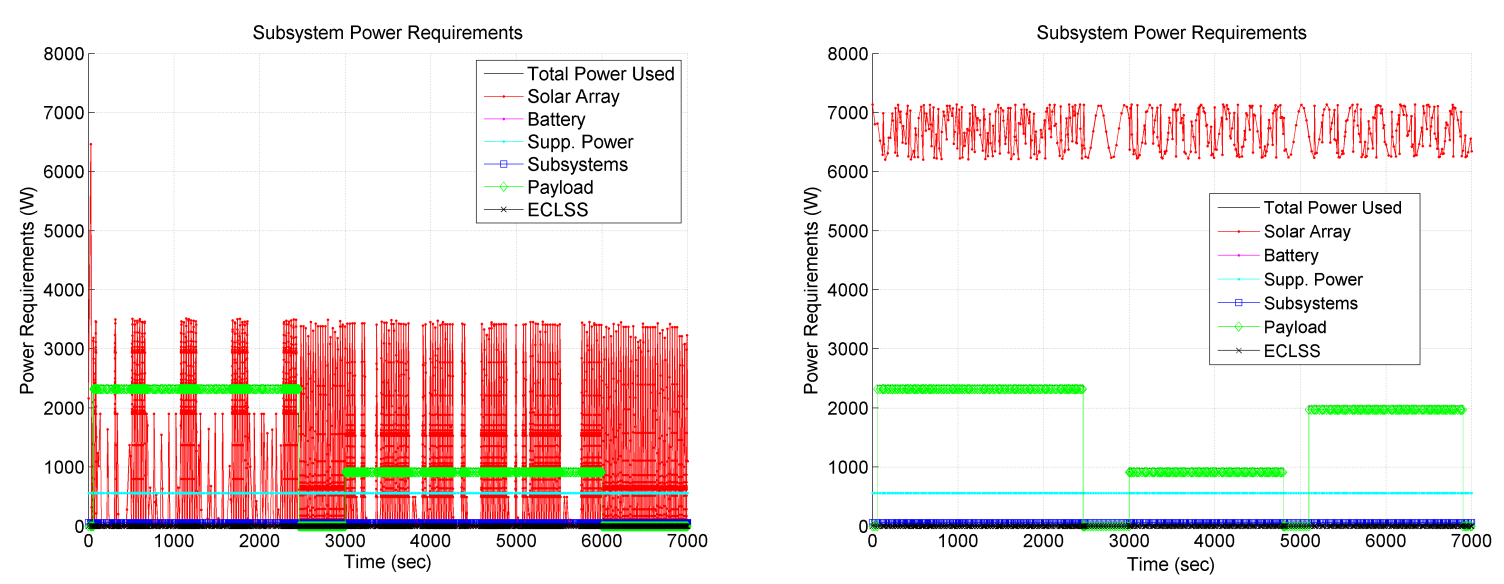

Figure 5. Visualization of a power production from various solar panel geometries. [Left] WP pointing with fixed panels, [Right] WP Pointing with Alpha articulation.

The geometries analyzed within SPASIM are separated into three different categories: fixed panels, alpha articulation, and alpha/beta articulation. Additionally, each of the previous geometries is analyzed in both sun pointing and waypoint pointing configurations. After deriving the best geometry, the optimum solar cell material is selected from: silicon, gallium arsenide, indium phosphorus, and gallium indium phosphorous. The solar-pointing and waypoint-pointing with alpha/beta articulation quickly arose as the most suitable for the MICEHAB mission. Figures 5 and 6 are visual representations of the power generation from each of the geometries. 

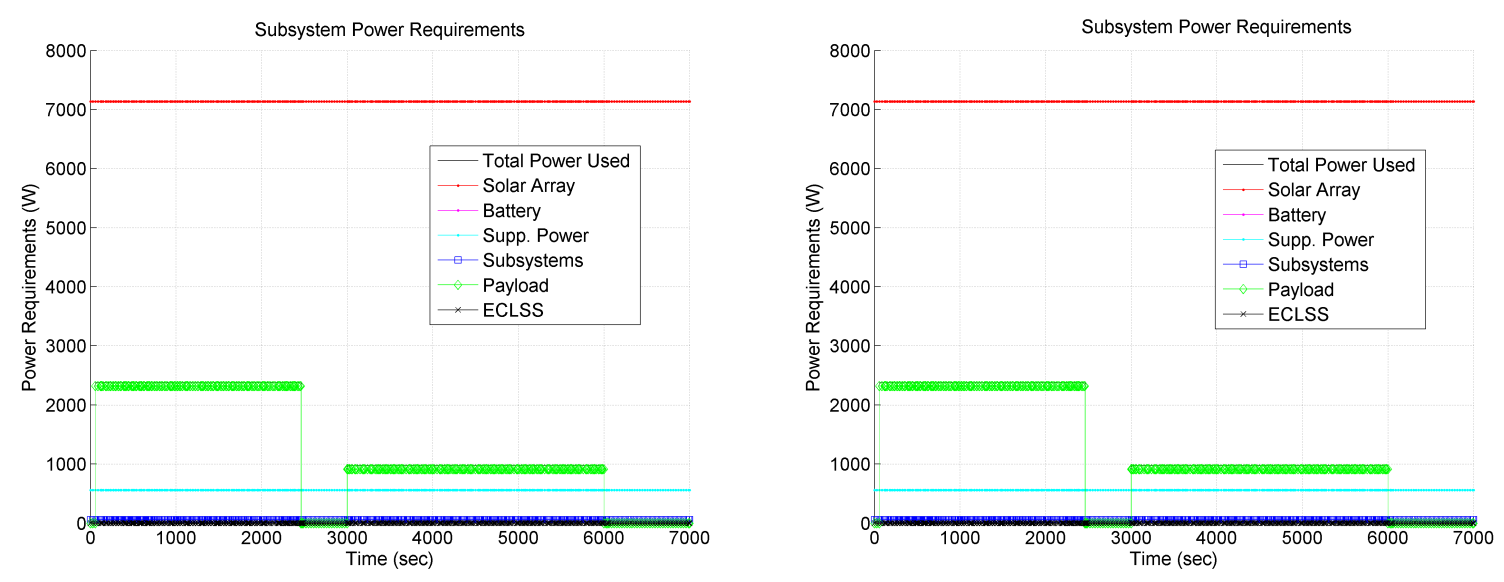

Figure 6. Visualization of a power production from various solar panel geometries. [Left] WP pointing with alpha/beta articulation, [Right] solar pointing with fixed solar panels.

Figure 5 shows that aiming at the waypoint without the dual-axial articulation supplies very sporadic levels of power. The continual rotation of the spacecraft prevented the solar panels from being able to correct to an angle which would maximize incident solar radiation. Due to the unreliable power generation both scenarios in Figure 5 are determined to be insufficient architectures for the MICEHAB mission. Figure 6 [left] also includes aiming at the waypoint, but the solar panels are capable of alpha/beta correctional adjustments. The large freedom of mobility allows for the solar panels to articulate individually and maximize the amount of incident radiation on the panel surface. While Figure 6 [left] reliably provides an adequate level of power, the complexity of coordinating the alpha/beta articulation of the spacecraft is a major disadvantage. In comparison, the solar pointing configuration of Figure 6 [right] causes the entire spacecraft to track the sun so the solar panels do not have to perform any correctional adjustments. Utilizing the Guidance, Navigation, and Control (GNC) of the spacecraft allows for a more simplistic control of the solar panels relative to the direction of incident solar radiation without sacrificing precision. While the GNC system will be used to point the solar panels at the sun, the communication antenna will be responsible for tracking the waypoint. Therefore, the MICEHAB will still be capable of precisely pointing the communication setup at the waypoint while the GNC system will be responsible for maintaining the maximum amount of incident solar radiation on the panels. Figure 6 [Right] is viewed as a more distributed system, where mission responsibilities can be shared among subsystems and mission success does not hinge on one single aspect of the design. For these reasons the solar pointing, fixed solar panel geometry was selected as the optimal design configuration for the MICEHAB mission.

\section{H. Habitat Design}

\section{H.1. Population Model}

The habitat design is primarily driven by the experiment goals and autonomous mouse care capabilities. The number of mice is a key driver for the size of subsystems and individual mouse enclosures. The growing size of the population, which is supported over the mission, must be determined as a first step in the design of the habitat. The Breeding Rodents Extraterrestrially to Enable Discovery (BREED) model ${ }^{37}$ is a Matlab-based tool used to evaluate the evolution and population management of the mice aboard MICEHAB. BREED uses Monte Carlo simulation methods to calculate and predict mice colony population, mass, and gender breakdown. Input parameters can be modified to predict ranges of population, masses, and gender breakdown in response to initial conditions, breeding strategies, and population control strategies. Table 5 shows the input parameters and their nominal values based on terrestrial C57BL/6J mice characteristics. ${ }^{17}$

The initial age of mice is assumed to be four months in order to ensure that the chosen mice are proven breeders prior to launch. Once on MICEHAB the choice of breeding strategy greatly affects the population progression. In this case, the nominal strategy is to introduce breeders as trios (one male and two females) when the mice reach sexual maturity. If conception is unsuccessful then failed breeders are reintroduced until all 10 females of a generation produce a litter. Then, at the weaned date, excess mice (those in excess 
Table 5. Input parameters and their nominal values. Values of the form (a, c, b) are triangular distributions with lower limit a, upper limit b, and mode c.

\begin{tabular}{lcc} 
Parameter & Value & Unit \\
\hline Initial Age & 4 & months \\
Fecundity & $80 \%$ & - \\
Death age & $(1,2,3)$ & years \\
Sexual maturity age & 7 & weeks \\
Days from introduction to conception & $(1,2.5,4)$ & days \\
Pregnancy duration & $(17,20,23)$ & days \\
Litter size & $(4,6,10)$ & mice \\
Gender & $50 / 50$ & - \\
Maximum number males to keep per generation & 5 & mice \\
Maximum number of females to keep per generation & 10 & mice \\
Initial male population & 5 & mice \\
Initial female population & 10 & mice \\
\hline
\end{tabular}

of the maximum number defined in Table 5) are euthanized; during which priority is given to maintain one female from each original maternal line. Those mice that are not euthanized are assumed to live to a natural death.
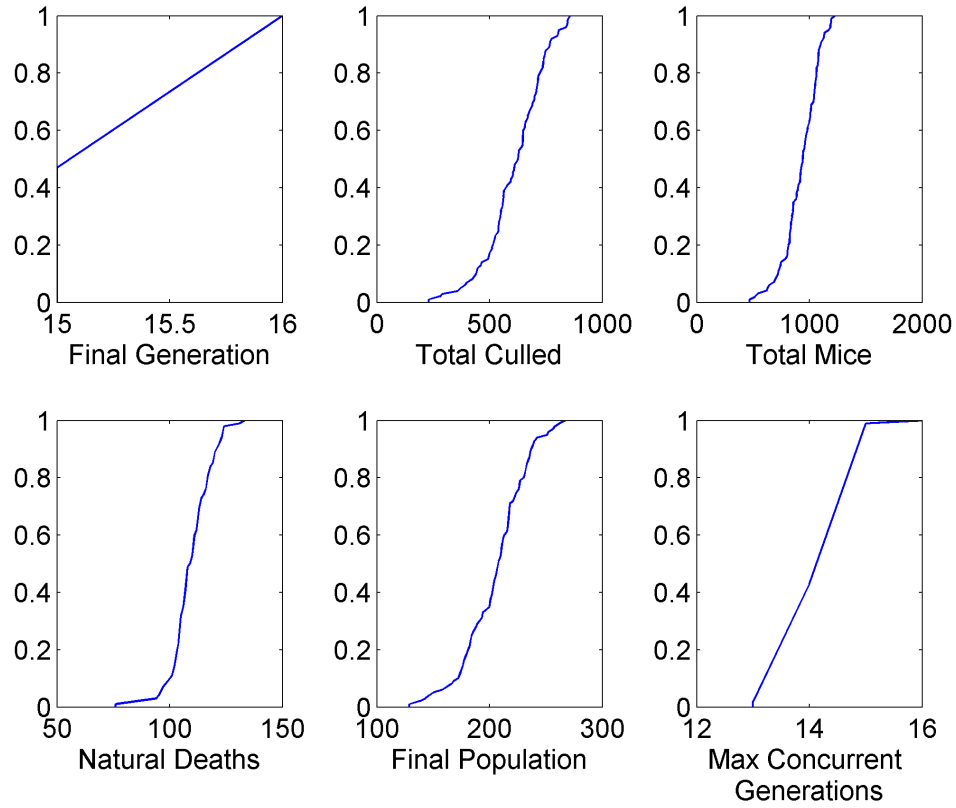

Figure 7. Cumulative distribution functions of various population characteristics.

Simulation results for 100 runs of a three year period using this breeding strategy and aforementioned input values are seen in Figures 7 to 9. Figure 7 provides cumulative distribution functions for a number of population parameters including the youngest generation at the end of the simulation, number of euthanized mice, total mice (alive or dead), natural deaths, final population, and maximum number of concurrent generations. Figure 8 provides a detailed gender breakdown of the MICEHAB population. Lastly, Figure 9 depicts MICEHAB population mass breakdown between live and dead mass. ${ }^{38}$ These resulting population, gender breakdown, and masses were then used to feed into an externally run sizing analysis to determine the habitat mass, power, and geometric requirements to maintain and sustain the desired population for a specified amount of time. The user can easily rerun the simulation to assess how a wide range of input variables impacts the final results. 

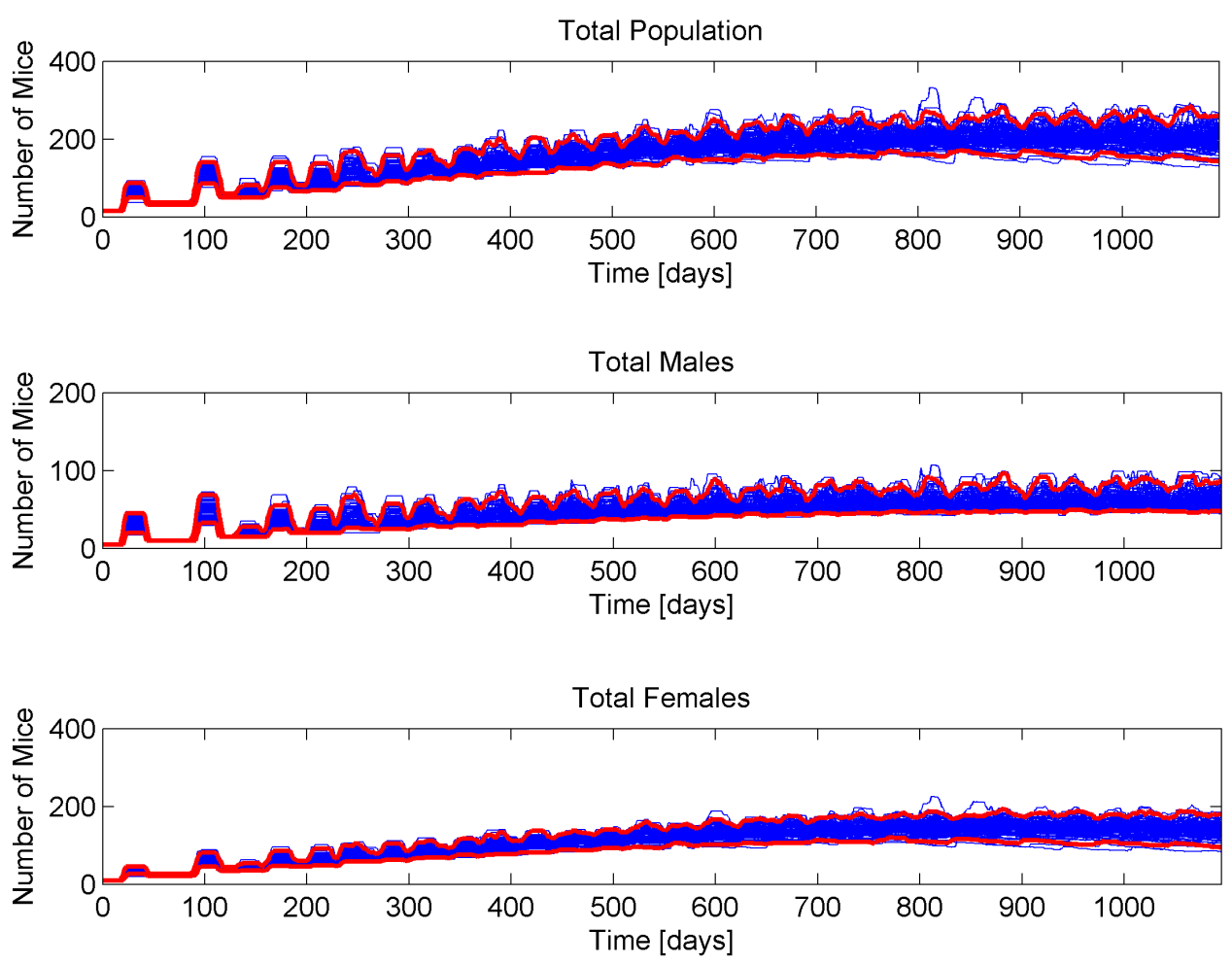

Figure 8. Mice population gender breakdown with $95 \%$ of runs falling between the red lines.

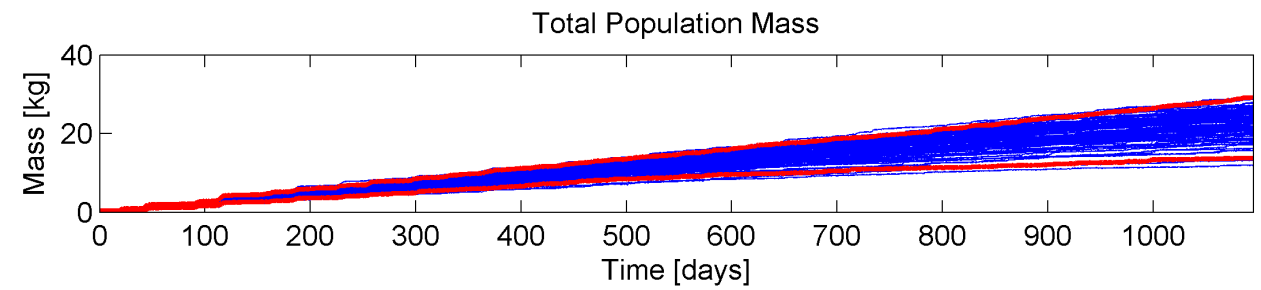

Total Live Population Mass

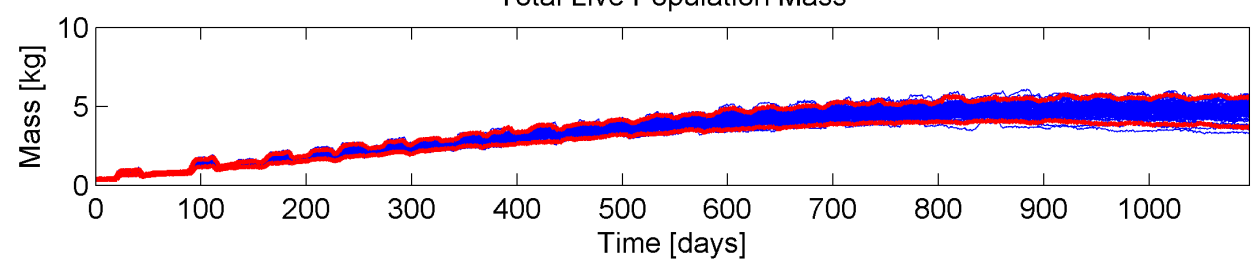

Total Dead Population Mass

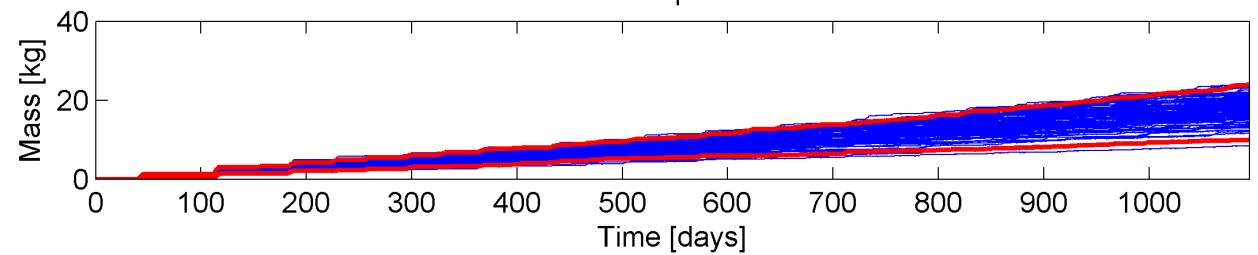

Figure 9. Mice population mass (kg) distinguished between live and dead used for sizing habitat with $95 \%$ of runs falling between the red lines. 


\section{H.2. Habitat Sizing Model}

Using this population model, mission design parameters, and the required functionality of the habitat, a preliminary estimate of the habitat mass, volume, and power is determined. The following assumptions are used to parametrically size the habitat portion of the MICEHAB vehicle:

- Mission duration of one year to coincide with human visits to the initial cis-lunar habitat in LDRO

- Mice population of approximately 200 peak and slightly greater than 100 average over a year

- Murine metabolic rates of $5 \mathrm{~g} / \mathrm{mouse} /$ day of each water and food which includes margin for wasted consumables

- Habitat diameter of approximately 3 meters

- One low-impact docking system with hatch for human access

- No windows

- Single fault-tolerant life support with partially closed air systems sized for 1 human crew (which is substantially oversized for 200 mice) and open loop water systems

- RCS sized for $125 \mathrm{~m} / \mathrm{s} \Delta-\mathrm{V}$ which corresponds to 5 spin up/down cycles or slightly less if some orbit maintenance is required

- $0.5 \mathrm{~m}^{3}$ freezer $(100 \mathrm{~kg})$ for return of samples

- Assume $15 \mathrm{~kg}, 0.05 \mathrm{~m}^{3}, 0.6 \mathrm{~kW}$ enclosure washer

- Maintenance robot: $50 \mathrm{~kg}, 180 \mathrm{~W}$ (peak), $54 \mathrm{~W}$ (nominal)

- Medical robot: $150 \mathrm{~kg}, 220 \mathrm{~W}$ (peak), $60 \mathrm{~W}$ (nominal)

- $\approx 200$ individual mouse enclosures: $1.57 \mathrm{~kg} /$ each $(1.07$ structure +0.5 enrichment)

- $50 \mathrm{~kg}$ for vehicle test equipment, $25 \mathrm{~kg}$ for tools, $100 \mathrm{~kg}$ for spare parts

- $50 \mathrm{~kg}$ for photography equipment (includes image processors)

Table 6. Mass breakdown of MICEHAB habitat module

Design Constraints/Parameters
Pressurized Vol.
Habitable Vol.
Atmospheric Pressure
Crew Capacity
Crewed Mission Duration
EOL Power Required
Total battery energy storage
Number of Batteries
Depth of Discharge
Power load during battery operation
ECLSS Closure - Water
ECLSS Closure - Air
Habitat Structure
Habitat Length
Habitat Diameter
Mass Growth Allocation
Project Manager's Reserve

\begin{tabular}{|c|c|c|}
\hline \multirow{4}{*}{$\begin{array}{r}18.9 \mathrm{~m}^{3} \\
6.1 \mathrm{~m}^{3}\end{array}$} & Category & Mass, kg \\
\hline & Structure & 1,302 \\
\hline & Protection & 57 \\
\hline & Power & 460 \\
\hline \multirow{2}{*}{$\begin{array}{c}101.4 \mathrm{kPa} \\
200\end{array}$} & Control (ACS/RCS) & 311 \\
\hline & Avionics & $32 \epsilon$ \\
\hline \multirow[t]{2}{*}{$365 d$} & ECLSS & 869 \\
\hline & \begin{tabular}{|c|} 
Air Subsystem \\
\end{tabular} & 434 \\
\hline \multirow{3}{*}{$\begin{array}{rl}6 & \mathrm{~kW} \\
13 & \mathrm{~kW}-\mathrm{h} \\
3 & \end{array}$} & Water Subsystem & 225 \\
\hline & Other & 210 \\
\hline & Thermal Control System & 337 \\
\hline & Crew Equipment & 401 \\
\hline \multirow{2}{*}{$5.4 \mathrm{~kW}$} & \begin{tabular}{|l|} 
Utilization \\
\end{tabular} & 345 \\
\hline & Growth & 1,316 \\
\hline Open & DRY MASS SUBTOTAL & 5,725 \\
\hline \multirow[t]{2}{*}{ Partially Closed } & Logistics & 590 \\
\hline & Food (Including Trays \& Wraps) & 365 \\
\hline \multirow{4}{*}{$\begin{array}{l}\text { Rigid Cylinder } \\
3.71 \mathrm{~m} \\
2.56 \mathrm{~m}\end{array}$} & Health Care Consumables & 50 \\
\hline & Spares & 125 \\
\hline & \begin{tabular}{|l|} 
Maintenance Items \\
\end{tabular} & 50 \\
\hline & ECLSS Consumables (Nominal + Contingency) & 500 \\
\hline \multirow{4}{*}{$\begin{array}{l}20 \% \\
10 \%\end{array}$} & Reserve and Residual Prop. & 62 \\
\hline & INERT MASS SUBTOTAL & 6,877 \\
\hline & Propellant & 283 \\
\hline & TOTAL WET MASS & 7,161 \\
\hline
\end{tabular}

Utilizing these assumptions, the preliminary estimated habitat sizing parameters and gross mass of $7.1 \mathrm{mT}$ are broken down in Table 6 . Here the habitable volume includes the volume of the enclosure, astronaut access corridor, and the translation aisle of the maintenance robot. The peak power requirement is approximately 6 $k W$ and the diameter represents the inner diameter of the pressure shell. Finally, enclosure and robot masses are included in the mass breakdown under Utilization. This mass breakdown is an initial estimate which 
is being refined by ongoing analysis to ensure the appropriate balance of increased functionality against launch vehicle constraints. Potential mass threats include underestimation of water/air line runs, required pressurized volume, and spares. One potentially overestimated system is the Environmental Control and Life Support System (ECLSS), which is difficult to model using human software tools.

\section{H.3. Interior Layout and Radiation Analysis}
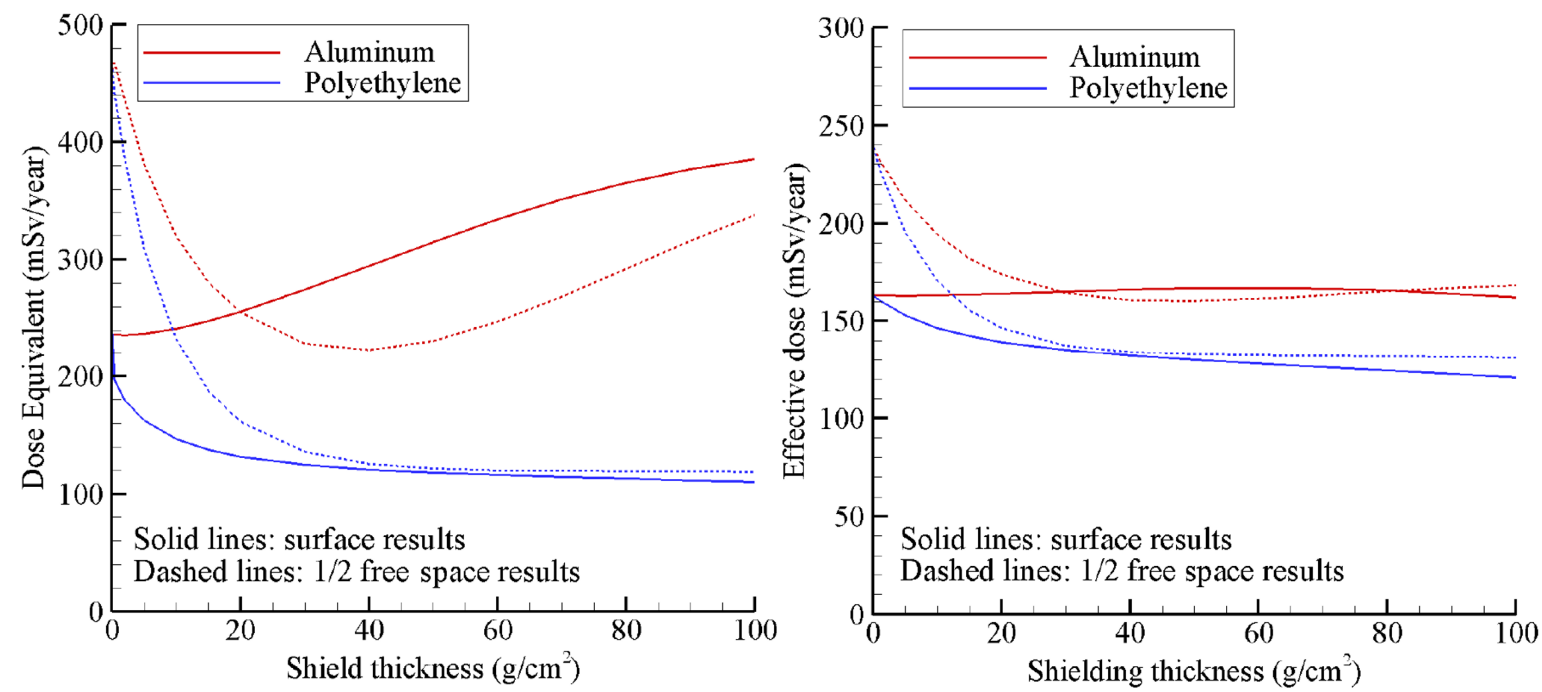

Figure 10. Comparison of surface exposed to $1 / 2$ free space exposure as a function of shield thickness, reproduced $^{39}$

In addition to sizing the habitat to provide the appropriate functionality, further analysis was performed to ensure that the interior layout of the animal enclosure rack system would be functional. The habitat rack structure system design is focused on three major considerations: radiation shielding, interchangeability, and space optimization. The first aspect, radiation shielding must be sufficient to simulate the radiation exposure similar to that of planned human spacecraft. Ideally, enough shielding would be provided to prevent confounding of the partial gravity results with unanticipated effects due to radiation, but there are several desirable investigations which would leverage a large animal colony exposed to the anticipated radiation levels humans would experience on exploration missions. Achievement of this radiation environment is a major driver of many constraints, most notably the radius of usable space.

MICEHAB will be located in cis-lunar space receiving continuous exposure from Galactic Cosmic Rays (GCR) as well as one or more possible Solar Particle Events (SPE).$^{39}$ Exposure from SPE can be effectively mitigated through appropriate shielding materials and thickness, however, GCR is only moderately reduced by shield optimization. ${ }^{40,41,42}$ The amount of GCR protection provided from aluminum and polyethylene shield thicknesses is shown in Figure $10 .^{39}$

Deep space human habitats generally achieve $10-20 \mathrm{~g} / \mathrm{cm}^{2}$ of shielding thickness leading to a minimum approximate dose of $300 \mathrm{mSv} /$ year using polyethylene. To maximize the usable space within the habitat and achieve the $10 \mathrm{mT}$ gross mass target, a target shielding thickness of approximately $10 \mathrm{~g} / \mathrm{cm}^{2}$ is desired for MICEHAB, resulting in a substantial effective dose reduction. This is deemed suitable for MICEHAB because a slight decrease in shielding thickness allows for more animals enclosures within the habitat. The shielding provided by the structure of a commercial cargo spacecraft is determined by dividing the mass of the spacecraft structure by the surface area of the spacecraft. Therefore, the shielding thickness provided by the spacecraft aluminum skin is determined to be $4.7 \mathrm{~g} / \mathrm{cm}^{2}$. A layer of subsystems and logistics approximately $0.21 \mathrm{~m}$ thick along the inner shell within the spacecraft provides the additional $5.3 \mathrm{~g} / \mathrm{cm}^{2}$ of shielding thickness required if distributed uniformly by density around the section of the habitat housing the animal enclosures. The combined shielding of the aluminum skin and the layer of logistics provides the desired 10 $\mathrm{g} / \mathrm{cm}^{2}$.

The next major consideration for habitat sizing is that of interchangeability in terms of the layout of the structure. Each animal enclosure will be identical in size and shape, thus making their slots within the rack system identical. For example, ventilation, water distribution, and cameras for visual observation of 
animals will be in the same location relative to each enclosure. This approach allows each enclosure to be interchangeable, and any enclosure can be plugged into any rack slot. Also, the interior of each enclosure is arranged identically, which makes the manipulation of items within each enclosure simpler. The habitat is also sized for a medical suite and an enclosure cleaning station, in which any of the identical enclosures can be inserted. All of the medical capabilities within the habitat will be located in the medical suite, which is operated by a medical robot. The maintenance robot transports the animals within their enclosures to either the medical suite (Please refer to Animal Enclosures section H.5 and Medical Robot section I.2 for details), to another enclosure bay within the rack structure, or to a staging area adjacent to the cleaning station where the mouse is removed robotically from the enclosure prior to cleaning of the enclosure.

Space optimization is also a major consideration due to volume and mass constraints. The most important space optimization consideration is ensuring enough space to house the maximum number of mice following enclosure dimension specifications set by veterinary specifications. ${ }^{19}$ In addition, volume for ECLSS, freezers, medical areas, power systems, avionics, and crew access pathways must all be protected. It is estimated that these systems will take up about one third of the remaining habitable volume inside the commercial cargo

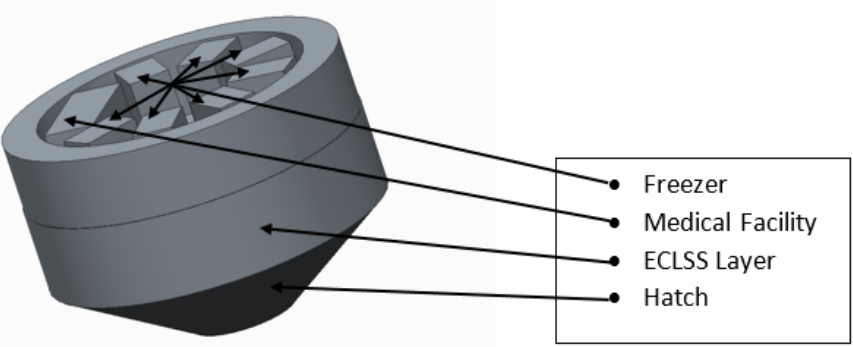

Figure 11. Habitat layer containing medical suite and freezers spacecraft (Figure 11). Volume will also have to be protected for astronaut tasks during the annual rendezvous with the cis-lunar human habitat, including removal of both waste and specimen samples, replacing used logistics, and fixing any issues with the mission critical systems such as ECLSS, the Thermal Control System (TCS), or the Power Control System (PCS).

Combining all of these considerations results in the interior layout of the enclosure area shown in Figure 12. A layer of logistics surrounds an interior structure which houses the enclosures in identical bays. Each layer of the habitat maximizes the number of enclosures to house up to 18 enclosures per level with a total of 11 layers. Each bay provides cameras, water, lighting and ventilation independent of the animal enclosures for simplicity. Subsystems supporting the habitat are located at the end of the layout near the crew access hatch to simplify annual maintenance, repair, and sample collection. On certain habitat levels, medical areas and enclosure washing stations replace enclosures. The following section describes the subsystems which are in-

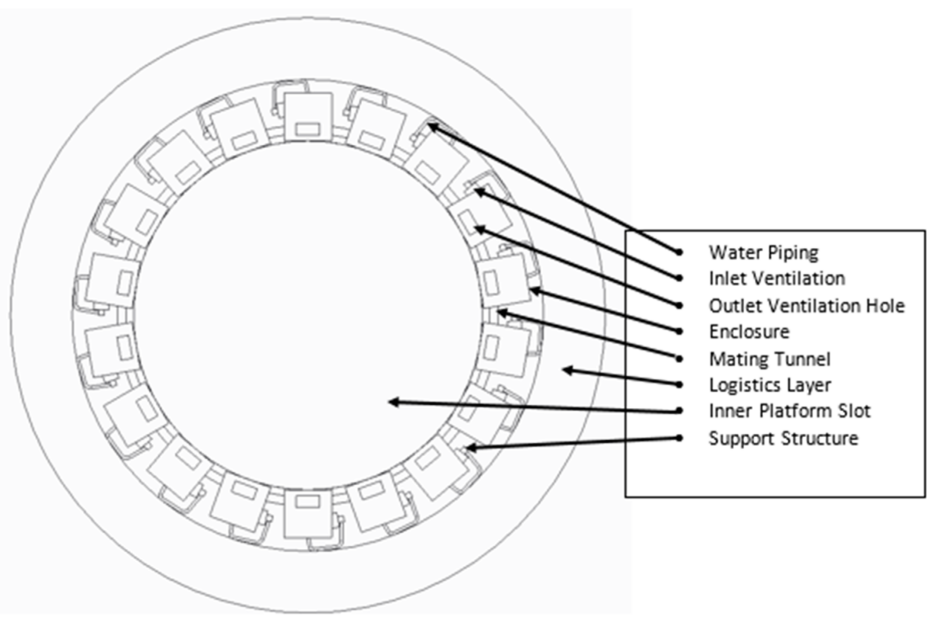

Figure 12. Enclosure layer cross-section cluded within this design.

\section{H.4. Habitat Layout}

Habitat layout are driven by the requirements of ECLSS, TCS, and PCS. Specific subsystems and functions within these systems are described in the baseline design to include: lighting, water distribution, ventilation, visual observation of animals, and mating tunnels. The lighting system will consist of a series of light emitting diodes (LED) to luminate the interior of the habitat and enclosures. These LEDs will be diffused across a surface to avoid point sources of light. The diffused lighting should not allow for more than $20 \%$ variance in light intensity within the enclosure. A lighting controller will enable the system to vary the overall light 
intensity to simulate a normal light cycle. Sources of light other than the LED lighting system (e.g. status lights or displays) will not be used in order to avoid inadvertent exposure to light during the dark cycle.

The animal water system will use a pressurized water tank to pump water from a reservoir to individual exit points within all of the mice enclosures. Within the enclosure, a lixit valve will be used to allow the mouse to have access to water. A lixit valve is chosen because it functions due to a pressure gradient; a lixit does not require gravity to function as designed. The lixit uses a stem that, if moved in any direction, will cause a valve to open and release water. The lixit is also designed to release a uniform flow rate, which allows for simple measurement in determining consumption. A simple circuit will be used to measure mouse water consumption. This circuit is disconnected until the mouse makes contact with the lixit or when the mouse drinks water. A low voltage signal is sent to a converter to monitor the consumption time. While processing these data, the difference between the two cases can be observed because a mouse's tongue and a mouse's tongue with water have different resistances. A summation of the consumption periods multiplied by the flow rate, which could be regulated to be constant, results in a net volume of water consumed that could be computed daily, weekly, or as so desired. This method has been tested and determined to be a viable method to interpret mouse's water consumption on Earth, ${ }^{43}$ and lixit valves are used on Rodent Habitat- $1 .{ }^{44}$

The ventilation system will consist of a centralized air flow control system which will distribute filtered air to each individual enclosure. Air from the enclosures will be exhausted into the cabin of the capsule. Positive air pressure will be maintained in each enclosure to ensure that unfiltered cabin air does not enter an enclosure. Visual observation is an important aspect of the mission; therefore, multiple cameras will be required to obtain the data required by a veterinarian and data desired for scientific purposes. The data required and desired using cameras are described in the Animal Enclosure section. A red, green, blue optical and two infrared cameras will be located in each animal enclosure bay allowing data collection from any mouse at any time. One infrared camera will provide redundancy in case of a malfunction with the other infrared camera. Mating tunnels will allow the mice to move between enclosures during veterinarian approved mating sessions. The tunnels will be closed by a gate the rest of the time.

\section{H.5. Animal Enclosure}

The MICEHAB design consists of individual housing enclosures to allow for controlled breeding and to reduce aggression between males. The floor and volume sizing for the enclosures, eight inches by eight inches floor and five inches high, meet the space requirements for a female plus a litter set forth by the Guide for the Care and Use of Laboratory Animals for comfortable quarters for mice. ${ }^{19}$ Inside the enclosures lixit valves (connected to the centralized automated watering system), similar to those used in laboratory vivariums, and solid food bars are used to provide for the mice's hydration and nutrition. ${ }^{13}$ The NASA Type 12 Nutrient Upgrade Rodent Food Bar meets the spaceflight requirements for adequate rodent nutrition. ${ }^{18}$

In addition, the mice are provided exercise wheels to help maintain health in the partial gravity and microgravity environments. Housing igloos will be situated in the enclosure to provide a nesting area for the thigmotaxic mice. This shelter area will be important for the nesting and weaning period in helping keep the female and pups huddled for temperature regulation and suckling. All pieces inside the enclosure, the food bar, exercise wheel, and igloo, are designed for both partial gravity and microgravity environments by being secured to the main structure using edible glue in the case of the food bar and latch systems for the wheel and igloo. This allows for the objects to be removed for periodic enclosure cleanings.

The interior surface area throughout the enclosure is almost entirely covered in a metal grid mesh similar to mouse enclosures on the ISS to allow easy maneuvering for the mice during micro-gravity. However, it is recommended to provide solid-bottomed caging with bedding for rodents as the rodents prefer to rest on a smooth surface. ${ }^{19}$ There is also evidence that rodents show eliminative behavior and only deposit feces in specific locations to avoid soiling their resting location. ${ }^{45}$ For this reason, the back half of the enclosure floor will be solid plastic and contain the nesting and eating areas. Additionally, the smooth floor surface allows for easier integration of weight sensors to measure mouse body weight and food consumption.

Waste removal is another important aspect of mice health. A disposable waste tray located below the front half of the metal grid mesh floor collects urine and feces and is removed by the maintenance robot on a monthly basis to reduce the ammonia levels from the urine. The used disposable waste trays can then be stored and preserved for analysis upon sample return. The ECLSS is responsible for regulating temperature, humidity, air quality, vibration, and acoustics as specified in Table 2 of the Rodent Research Science Requirements Envelope Document: Animal health maintenance requirements ${ }^{46}$ (through all phases of the mission unless otherwise specified). The model in Figure 13 depicts the baseline enclosure design. 
There are a number of metrics needed to assess the general health of the mice population and to obtain scientific data from this system that must be incorporated into the enclosure design. Mark III listed a number of concerns, risks, and knowledge gaps as well as possible risk mitigation approaches to consider for mammalian reproduction in space. ${ }^{4}$ MICEHAB aims to address these concerns, risks, and knowledge gaps as well with the additional challenge of autonomous control systems.

The primary veterinary requirements can be met through visual examination using the visible light and infrared spectrum video cameras situated in the outer structure aimed at the enclosures. These parameters include respiration, skin, fur, nose, eye, and extremity condition as detailed in Table 4.11.2.1 of the Rodent Habitat Project Mark-1: Visual/Video Animal Health Check Parameters. ${ }^{18}$ Physical activity will also be assessed visually according to Table 4.11.2.1 of the Rodent Habitat Project Mark-1 as well as with image processing or encoding systems to measure exercise wheel rotations. ${ }^{18}$ Body vitals for the mice, including heart rate, blood pressure, body temperature, and breathing rates can be measured using implantable telemetry devices similar to those used in the Bion-M experiment. ${ }^{13}$ However, considering the multigenerational concept of MICEHAB, non-invasive approaches for measuring these vitals using the infrared cameras would be more appropriate. Other indicators of general health include body weight, body length, and food and water consumption. A weight sensor located in the nesting area will provide weight information for both the individual males and females as well as the pups during the nesting and weaning period.

Eye tracking may provide valuable information in preflight testing and assessment of the enclosure design. The real-time, self-calibrating technology could non-invasively track a mouse's gaze using the camera system already surrounding the enclosures. ${ }^{47,48}$ This gaze information could be paired with other physiological stress indicators to reveal stressful areas of interest. Minimizing the stress level of the mice on orbit will be very important to the success of the MICEHAB mission. In addition to these general health parameters, general science parameters will provide valuable information about mouse growth and development in partial gravity. Each stage of the mouse life cycle, including mating, pregnancy, nesting and birth, nursing and weaning, growth, and maturation, has measurable metrics and specific procedures to verify and ensure proper development.

Mating: Once the mice reaches breeding age, typically about 6 to 8 weeks ${ }^{20}$ for the females, the gates to the connecting tunnels will be opened for temporary cohabitation to allow for mating within a mating trio. Typically, behavioral estrus, mating, and ovulation take place in the dark cycle so the gate opening will be appropriately timed. ${ }^{49}$ Ideally, the solid gate would be opened prior to the time of mating, leaving a metal grid mesh gate, to allow for olfactory communication and ultrasonic vocalizations indicating mating communication between the male and female. ${ }^{45}$ Finally, to confirm that conception has occurred the cervix will be examined for the vaginal plug which will persist 12 to 14 hours after mating. ${ }^{50}$ This visual examination would ideally be performed non-invasively using the cameras surrounding the enclosure. However, it is possible that a restraint and probe may be necessary for examination either in the enclosure or in the medical suite.

Pregnancy: Stereotypic rounding of the belly indicating pregnancy will become fairly obvious between day 9 and 11 in young females following fertilization ${ }^{50}$ and will be monitored visually using the cameras surrounding the enclosure. In addition, the mother's body weight can be used to track progression in the pregnancy. The gestation duration will also be noted to compare to the terrestrial standard which typically lasts 19 to 21 days. ${ }^{20}$ For a more in depth analysis of fetal development, the female mice may be transported to the medical facility for ultrasound imaging of the fetus.

Nesting and Birth: Nesting is a very important behavioral aspect of the mouse reproductive cycle. In this phase leading to birth, the pregnant dams provide limited nesting material for the igloo area. This artificial 
material must be safe for mouse digestion and manageable by the waste filtration system. Prior to birth, the male mice must be removed from the female enclosures to reduce possible cannibalism of the litter. ${ }^{20}$ The gating system will be opened to allow for natural separation of the males and females. However, it is possible that the males will need to be relocated using the maintenance robot's handling capabilities. The size of the litter could vary from 4 to 12 pups.

Nursing and Weaning: To allow for a healthy nursing stage, all handling of the mother in the first two days post-partum will be avoided. ${ }^{50}$ Lactation is expected to last about four weeks, and during this time the mother will receive supplements to provide a nutritious diet with higher fat content. ${ }^{49,50}$ Ultrasonic vocalizations, indicating pups in distress, for example if they fell out of the nest, will be recorded and analyzed to further monitor the health and well being of the pups and mother. ${ }^{45}$ Weaning is a critical time for the survival of the pups. If the pups are weaned too early, they may not survive, and if they are weaned too late, siblings may mate. ${ }^{50}$ While the weaning age is typically 21 days, it will be vital to monitor the growth and development of the pups to ensure proper weaning. ${ }^{50}$ This will be done by using the weight sensor in the igloo to monitor body weight and the cameras around the enclosure to monitor body length and physical characteristics including body temperature. In addition, careful observation of the pups' physical behavior and activity when the lid of the enclosure is removed can indicate readiness to be weaned. ${ }^{50}$

Once it is time to wean the pups there are a number of other procedures that will need to be performed in the medical facility, including more accurate weight and length measurements, gender identification, and individual identification and ear tagging. Finally, population control will occur after weaning by randomly selecting males and females for euthanasia in the medical facility. It is important not to cull the litter to less than three or four mice during nursing because this could cause the mother to stop lactating. ${ }^{50}$

Growth and Maturation: The young mice will then be placed in individual enclosures and their body weights will continue to be monitored. The mice will develop to sexual maturity before being mated again. The vaginal opening in the females is open reported by four weeks of age and can be checked by visual examination of the cervix. ${ }^{49}$ The estrous cycle, which repeats every four to five days, also indicates maturity and willingness to mate. This cycle is interrupted by pregnancy and pseudo pregnancy and can be assessed by visual examination of the cervix or by taking a vaginal smear in the medical facility. ${ }^{49}$

\section{Autonomous and Robotic Mission Capabilities}

MICEHAB will house two robotic systems. One is a maintenance robot that performs tasks on a platform that travels vertically through the central core of the habitat, and the other robot performs medical tasks and is located in the defined medical suite.

\section{I.1. Maintenance Robot}

The maintenance robot will perform tasks such as: handling the mice and the mice pups, moving the enclosures in and out of the rack structure bays; accessing and moving logistics, removing and replacing waste trays, manipulating items in the enclosure, removing the enclosure lid, replacing the water valve, and general preventative and corrective maintenance of the ECLSS, TCS, and PCS.

In order to accomplish these tasks, the maintenance robot will need multiple capabilities (Figure 14). A platform operating on a rail/conveyer system is required to move the maintenance robot vertically through the central core of the habitat module. This platform will also allow the robot to translate horizontally on each level to reach and interact with the enclosures, and to be able to reach and manipulate logistics packages located behind the enclosure. Dynamic rails attached to the base of this robot will be used to latch onto enclosure for movement and manipulation. Additionally, the maintenance robot will be capable of rotating 360 degrees about the vertical axis of the rail system/platform, in order for the robot to interact with every habitat enclosure and logistics storage area, as well as the medical suite, the refrigerator and freezer, and the ECLSS system.

The maintenance robot will likely have multiple arms or appendages. A Robonaut/Valkyrie-type hand that is capable of handling the mice and pups is required at the end of at least one of these appendages. NASA has led the way in the development of highly advanced robotic hands and arms of the Robonaut 1 , Robonaut 2, and Valkyrie systems. Integration of these dexterous hands on strong robot arms allows for work with objects, interfaces and tools built for humans. ${ }^{51,52}$ Robonaut-like hands can handle natural objects

like rocks or soft fabrics like thermal blankets and perform dexterous movements to operate interfaces like switches, latches, knobs, handles, buttons, drawers, lids, hoses and cables. ${ }^{51,52}$ It is reasonable to assume 
that advanced capabilities of a Robonaut/Valkyrie-type hand can grasp and scoop mice delicately enough as not to cause harm to the animal.

Another arm on the maintenance robot will be capable of exchanging and utilizing various end effectors to perform specific preventative maintenance tasks like replacing ECLSS filters, and corrective maintenance such as removing a faulty water valve and replacing it with a new valve. Redundant robotic arms will be stowed in the logistics area and will be used as replacements in case of a failure within the maintenance robot. These replacement arms would move along the rail/conveyer system to be installed on the robot by a working robot appendage. Alternately, there may be enough room in the central core for an entire redundant maintenance robot system to be installed on the underside of the platform to be used as a backup if the primary robot fails.

Earth-based robots already exist that perform the same functions as the MICEHAB robot. Laboratory management robots, similar to those developed by Nikkyo Technos and Yaskawa Electric, ${ }^{53}$ are automated to perform human-like tasks associated with the management of large rodent colonies. These robots are used by pharmaceutical companies and research institutions to deliver food and water, move enclosures, and change waste trays. Earth-based warehouse automated storage and retrieval systems such as Dematic Multishuttle $2^{54}$ move multiple boxes of similar size and shape through a warehouse via rails and conveyer systems. The MICEHAB maintenance robot design is influenced by these Earth-based systems, and can be operated as a mostly autonomous system through use of advanced autonomous and robotic capabilities that are currently being designed to enable human exploration mission to Mars.

\section{I.2. Medical Robot}

Veterinary functions and science return will play an integral part in colony management and achieving mission objectives. Therefore, a medical robot will be housed in the medical suite to perform sensitive veterinary and science related functions. The remote operation of this robot system is made possible by advances in terrestrial telemedicine. Medical robots like the da Vinci ${ }^{55}$ and $\mathrm{M}^{56}$ proved remote operation of complex medical procedures is possible. As of 2013, over 1.5 million surgeries have been performed with the da Vinci system, including $80 \%$ of all cancer-associated prostatectomies that year. ${ }^{55,57}$ Application of these systems to spaceflight is already underway, with parabolic flight testing and long-distance remote operation performed underwater at the Aquarius Habitat. ${ }^{58}$ Telerobotic surgery capabilities demonstrated in these and other experiments provide a window into what veterinary and science return functions may be installed in the MICEHAB medical suite.

Specifications for the medical suite are determined by the veterinary and science return requirements. Approximately 45 veterinary conditions may need further examination for treatment options and capabilities. Several of these are identified as "shall" priority primarily owing to their importance in breeding management, meaning that ability to treat will be necessary for success of the MICEHAB mission and will be manifested in the veterinary suite design. The remaining conditions are important for colony health and management but will be planned with the consideration of the relatively small impact of a loss of a few mice on mission success and sample statistical significance.

Table 7. Veterinary conditions that need further examination for treatment options and capabilities.

\begin{tabular}{|c|c|c|c|}
\hline Procedure & Importance & Procedure & Importance \\
\hline \multicolumn{2}{|l|}{ Vitals Measurements } & Dissection & Shall \\
\hline \multirow{5}{*}{$\begin{array}{l}\text { - Heart Rate } \\
\text { - Breathing Rate } \\
\text { - Blood Pressure } \\
\text { - Body Temperature } \\
\text { - Body Weight }\end{array}$} & \multirow{5}{*}{ Shall } & Visual Examination of Genital Region & Shall \\
\hline & & Blood Collection & Should \\
\hline & & Ultrasound Imaging of Fetus & Should \\
\hline & & Artificial Insemination & Should \\
\hline & & Caesarian Section & Should \\
\hline \multicolumn{2}{|l|}{ Drug Deliver } & In Vitro Fertilization & Should \\
\hline \multirow{4}{*}{$\begin{array}{l}\text { - Anesthesia } \\
\text { - Analgesia } \\
\text { - Euthanasia } \\
\text { - Antibiotics }\end{array}$} & \multirow{4}{*}{ Shall } & Surgical Implantation of Telemetry System & Should \\
\hline & & Vaginal Smear Cytology & Should \\
\hline & & Boone Densitometry & Not Concerned \\
\hline & & CT Scan & Not Concerned \\
\hline
\end{tabular}


For all examinations and experimental measurements that cannot successfully be performed in the animal enclosures, transport to the medical facility may be necessary. While transport will be minimized to reduce stress, certain procedures will require the capabilities of a dedicated medical robot and suite. These examinations are a subset of the science requirements that have been identified and prioritized based on importance to mission science goals (Table 7). Examinations specific to the medical suite include those critical to life cycle management such as investigation of vaginal plug, pup's gender, vaginal opening, and estrous cycle stage. ${ }^{59}$ Performing vaginal smear cytology to identify vaginal cornification and for further study of the estrous cycle will also require fine, dexterous movement from the medical robot as well as a 40x objective lens for immediate analysis or preservation for sample return. ${ }^{60}$ Ultrasound imaging during gestation would allow for assessment of fetal development by phenotypic analysis including diameter of the gestational sac, crown-rump length, fetal heart activity, and blood flow within the umbilical cord. ${ }^{60}$

Additionally, procedures including artificial insemination, in vitro fertilization, caesarian section, and sperm and egg collection and cryopreservation provide risk mitigation and overall scientific benefit. General sample collections including blood draws, biopsies, and dissections will also occur in this medical suite. These samples will be properly stored and preserved so that analysis such as DNA isolation and genotyping by gene expression Real-Time Quantitative Reverse Transcription PCR can be performed on Earth.

To meet science return requirements, cryogenic storage will be included for tissue preservation. The ISS currently uses several freezers, including the Microgravity Experiment Research Locker Incubator, the Minus Eighty-Degree Laboratory Freezer for ISS, the General Laboratory Active Cryogenic ISS Experiment Refrigerator (GLACIER), and the Polar refrigerator, which have demonstrated reliable cryogenic sample storage in orbit. Based on the internal cold storage space to total freezer space ratio of $27 \%$ (approximately that of the GLACIER and Polar $-80^{\circ} \mathrm{C}$ capable systems) and the requirement for one year's worth of mice tissue samples (approximately $0.04 \mathrm{~m}^{3}$ cubic inches), MICEHAB has ample volume $\left(0.5 \mathrm{~m}^{3}\right)$ allocated to cryogenic storage systems and internal cold stowage.

The primary control mode of the medical robot is teleoperation. Telepresence, an immersive version of teleoperation, will be used by veterinarians on the ground to perform procedures using the MICEHAB medical robot. The MICEHAB facility will be in orbit about the Moon, thus communication delays of approximately 2 seconds may impact the teleoperation performance capabilities of the robot. Therefore, an advanced capability for the medical robot to sense and react autonomously to a real time anomaly is highly desired. NASA Extreme Environment Mission Operations (NEEMO) 7, 9, and 12 included experiments to evaluate the performance of telerobotic systems and their potential for use in extreme environments. ${ }^{61}$ Tested systems include the Automated Endoscopic System for Optimal Positioning, the M7, and the RAVEN surgical systems. These operations investigated factors such as robot proficiency, surgeon and non-surgeon performance on simulated surgery, and real $(4,500-\mathrm{km}$ distance) and simulated time delay to mimic EarthMoon communications. ${ }^{58}$ NASA has also investigated use of robotic surgery systems in zero-gravity conditions with the 2007 DC-9 parabolic flight testing of the M7 robot system performance on simulated surgical tasks. ${ }^{58}$ Altogether, these experiments have demonstrated that technical hurdles such as communication, microgravity, and robot dexterity are not insurmountable, and these systems show promise for use in delivering remote surgical capabilities to orbital locations.

MICEHAB sizing limitations and rodent subjects necessitate a small and compact robotic system. To this end, NASA already supports research of miniature surgical robot systems through the Experimental Program to Stimulate Competitive Research (EPSCoR) and Reduced Gravity research at the University of Nebraska Robotics and Mechatronics Lab. The Nebraska team has demonstrated the use of a miniature in-vivo robotic surgery platform to perform multiple porcine model surgeries. ${ }^{62}$ The in-vivo nature of this system places the robot inside the insufflated abdomen through a single incision and has driven miniaturization to fit the two robotic arms within a small 5.5-inch chamber. ${ }^{63}$ Power requirements are expected to be much less than $30 \mathrm{~W}$, and mass is decreased compared to other robotic surgery systems with the entire arm and external computers weighing approximately $10 \mathrm{~kg}$, compared to $15 \mathrm{~kg}$ for just the M7 robot (not including computer controls) or $22 \mathrm{~kg}$ for the RAVEN. ${ }^{58,63}$ This system is currently being studied for use in microgravity through parabolic flight testing, with the first attempt of 28 parabolas completed in April 2014. ${ }^{63}$ Given the dimensions of existing small surgical robots, such a system will fit within the allocated MICEHAB volume $\left(0.07 \mathrm{~m}^{3}\right)$, mass $(150 \mathrm{~kg})$, and nominal power $(60 \mathrm{~W})$.

Testing performed on NEEMO missions show that while time-delay modeling between Earth and the Moon increases operation time and error rate, delicate surgical operations can still be performed. Future research is needed to determine whether existing systems are capable of performing on the small rodent sized 
organs, if other highest priority (shall) veterinary requirements can be experimentally achieved, and how latency and gravity influence the success of operations.

\section{I.3. Autonomous Habitat Functions}

MICEHAB is designed so that most of the systems can be maintained autonomously. For example, the food and water delivery system and removal of waste will operate autonomously. The food bar delivery system will automatically dispense a new food bar after a determined amount of time. Water from a central reservoir will flow to valves installed in each habitat enclosure. A sensor located near the valve will regulate water flow and measure water consumption. System software will track water consumption and will send an alert if consumption is outside of predefined limits. The system software will survey and assess the problem and process in real time if the robot needs to replace the water valve or if the animal's health is compromised. System software will command the maintenance robot to remove and then replace the waste tray on a predetermined schedule. Animal movements will be tracked autonomously, and an alert will be sent if the animal's movements are outside of predefined limits. The lighting inside of the enclosure will operate autonomously and follow prescribed time line appropriate to specific mice life cycle stages.

Advanced software architectures for robotic systems are required to achieve the desired level of autonomy on MICEHAB. Such an architecture is integrated into the habitat and vehicle design beginning in the conceptual phase and is implemented through a sophisticated framework like the one currently under development at NASA Langley Research Center's Autonomy Incubator (AI). The central scientific goal of the AI research initiative is to understand the principles that make intelligent behavior possible on robotic platforms. This is accomplished by analyzing both natural and artificial systems, formulating and testing hypothesis, and designing, building, and evaluating mechanical computational systems that perform tasks whereby having intelligence is regarded as necessary. ${ }^{64}$

The Autonomous Entity Operations Network (AEON) framework developed by the AI utilizes Unmanned System platforms developed by third parties to integrate into a single system which provides evaluation and testing, mission planning and operation, and out-of-the-box autonomy and data fusion capabilities. The first goal of AEON is to develop a cross-platform, extensible, onboard software system that provides autonomy at the mission execution and course-planning level, a highly configurable data fusion framework sensitive to the platform's available sensor hardware, and plug-and-play compatibility with a wide array of computer systems, sensors, software, and controls hardware. The second goal of AEON is to develop a ground control system that acts as a test-bed for integration of the proposed heterogeneous fleet and allows for complex mission planning, tracking, and debugging capabilities. ${ }^{65}$

The AEON Architecture expresses itself as a hybrid architecture pulling in elements from both the SensePlan-Act and Subsumptive (behavioral) architectural approaches, and is designed to achieve the following high-level goals: ${ }^{65}$

- Rapid integration of both in-house and third party software modules

- Platform agnosticism

- A system that is high performance, fault tolerant, and redundant

- A high level of modularity with extremely loose coupling to achieve reusability and flexibility

- Abstraction of networking details and boilerplate from researchers and third parties

- Distributed communications that enable software to run anywhere

- Interoperability via well-defined communication interfaces based on standards

As an overview, the architecture is split into four layers:

- Data Production

- Executive

- High-Level Behavorial

- Service

The Data Production Layer functions as a funnel that pulls in processed sensor data from several sensor processing nodes that handle outputs from real sensor hardware or the outputs of other sensor processing nodes. The Executive Layer contains modules which are responsible for handling the permissions of other nodes within the system, making critical operation decisions, and handling overall system status and capability degradation. Following the Executive Layer is the High-Level Behavior Layer (HLBL). The HLBL 
contains nodes that chain together nodes in the final layer, the Service Layer, to perform more complex behaviors than any single service on its own could achieve. Use of these four architectural layers for the MICEHAB model demonstration is described in Section IV.

\section{I.4. MICEHAB Capabilities the Enable Human Exploration Missions to Mars}

Advancements to current state-of-the-art (SOA) autonomous and robotic mission operations are required in order to enable Mars exploration missions. Critical technologies and capabilities have been identified for development, and MICEHAB offers a platform for which these advanced capabilities can be tested, refined, and then scaled for human missions. Autonomous mission operations require advanced capabilities to monitor displays, perform procedures, execute timelines, and mange faults with time delays greater than 10 seconds. $^{3}$ The defined MICEHAB autonomous functions performed with and without the maintenance robot are dependent upon these same advanced capabilities that are required to enable human missions to Mars, but with delays of less than two seconds. Designing and testing these systems in the lunar vicinity is an important step forward in advancing autonomous capabilities.

Complex events such as rendezvous, docking, and proximity operations all require advancements beyond the current SOA in autonomy, robotics, and communication and navigation systems for successful missions to Mars. These operations currently involve assistance from Mission Control but executed by human crew with the support of automated guidance and proximity operating systems. MICEHAB presents an opportunity to test and refine these systems during rendezvous and docking with the initial cis-lunar human habitat.

Robotic mission operations require advanced capabilities in the areas of manipulation, human-robotic interactions, sensing and perception, and autonomous rendezvous and docking. ${ }^{3}$ Dexterous manipulation and sample acquisition and handling require advancements within the area of manipulation. The MICEHAB Robonaut/Valkyrie type hand mounted on the maintenance robot will be more advanced than the current Robonaut 2 SOA hand and will test dexterous manipulation, and the medical robot will test sample acquisition and handling. Within the area of human-robotic interactions, multi-modal interactions will be tested on MICEHAB through enhanced robot situational awareness when interacting with the mice. Interaction with teleoperated or supervised autonomy modes with time delays of less than two seconds will be tested using the medical robot.

The EMC architecture involves pre-deployment of assets prior to exploration operations, which will necessitate the maintenance of those assets in a dormant state for a period of time prior to arrival of the crews in order to preserve vehicle systems and associated consumables. The dormant period could range from several months to several years, therefore, robotic systems will be needed to perform caretaking operations and conduct preventative and corrective maintenance while the crew is not present. An approach using robotics in this manner to maintain and operate pre-deployed equipment is defined in the paper "Robotic Solutions for Exploration, Earth and Space". ${ }^{51}$ Using ISS servicing data extrapolated to deep space facilities, the paper estimates that a squad of robots could handle maintenance levels on the order of 30 hours per week. The paper also estimates that robots will take 10 or 20 times longer to perform tasks than crew members; however, on-orbit testing planned for ISS will improve this estimate. Therefore, it is reasonable to assume that robots are a viable option for maintenance and caretaking of MICEHAB. Additionally, MICEHAB autonomous/robotic operations, particularly those performed by the maintenance robot, are directly applicable to EMC dormant period operations and can provide a testbed for the associated capabilities and operations, thus enabling Mars exploration mission capabilities.

\section{Model Demonstration}

To visualize and test certain concepts within the habitat, a scaled model was created for demonstration purposes as shown in Figure 14. The demonstration allows the concept definition team to better visualize and modify the early stage design. A cross-section of the vertical, rotating system of the habitat module, as described in the Baseline Design Section III, was built for the demonstration.

\section{A. Rack Structure Design}

A two-level, semi-cylindrical structure, containing six slots for enclosures (three slots per level), was built as a model to represent the baseline design. Six enclosures are sufficient to demonstrate vertical and rotational capabilities of the cylindrical habitat concept. The design and dimensions for this demonstration represent 


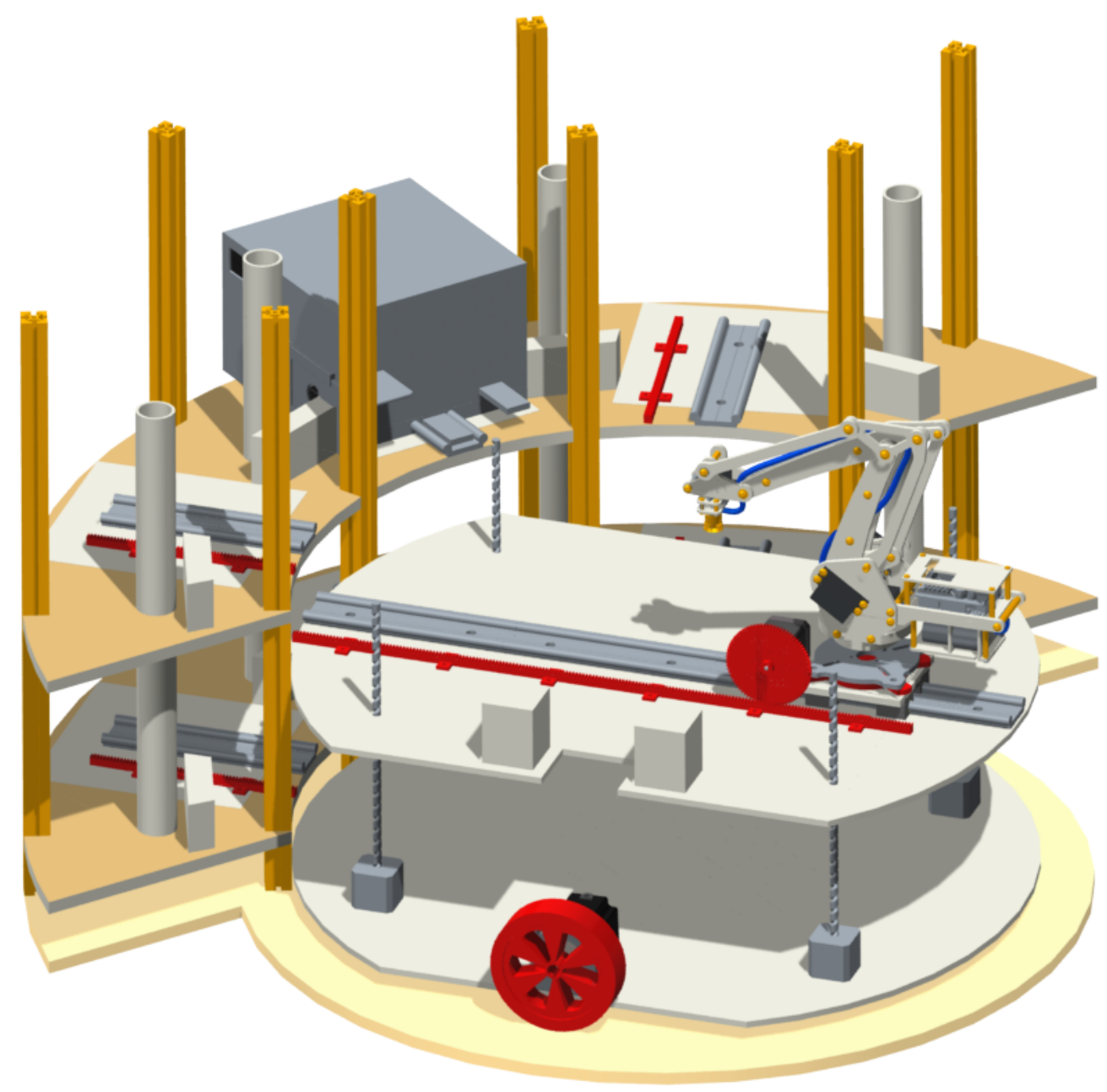

Figure 14. MICEHAB Scaled Mock-up Demonstration Setup
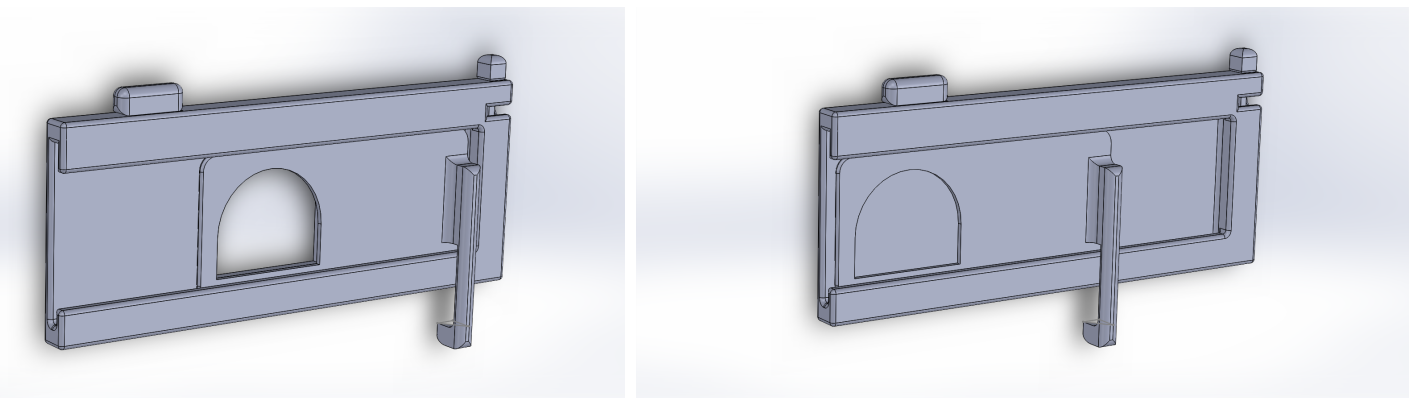

Figure 15. Gate assembly in open [left] and closed configurations [right]. Enclosure front towards the right side of image. In the closed configuration, a spring held within the top portion of the frame holds the sliding gate card in place. The card presents a flat surface which mice are unable to grasp or bite. In the open configuration, a linear actuator presses against the hockey-stick shaped tab and compresses the spring to permit entry into the gate segment and passage between enclosures. 
that of an early iteration of the integrated rack structure that holds individual enclosures. This structure is outfitted with a limited set of subsystems to test functions required in the baseline design: lighting, observation monitoring system, mating transportation, and ventilation.

The lighting system demonstration consists of LEDs that are on a similar timed system as they would be in the actual baseline design following a 12-hour light and 12-hour dark schedule. Future demonstrations will feature single visible-light LEDs in each enclosure that will illuminate to indicate when an action is performed. These LEDs will change color to provide visual cues that represent operation phases of certain functions. The observation monitoring system is demonstrated with partial functionality. An infrared and optical camera are placed in the upper inner corners of one enclosure slot. These cameras serve two purposes: 1) to make observations of the interior of the enclosure, and 2) to function as part of the autonomy demonstration.

The mating tunnels are an important feature of the structure; these allow a female and male mouse to access one another's enclosure during a specified mating window. Therefore, the entrances to the tunnels need to be closed by a gating system when the animals are not allowed to mate and also when the enclosure is removed from its slot. Figure 15 shows the model gate designed for the demonstration. The model gate system utilizes a linear actuator and spring system to slide the gate to an open or closed position. A system such as this could be used in the actual baseline design if it were outfitted with a sensor to detect if a mouse was obstructing the entrance similar to that of an optical sensor on an automatic sliding door.

\section{B. Model Enclosure Design}

The model enclosure demonstrates some of the major design elements from the baseline enclosure design including the exercise wheel, igloo, gate system, waste tray, and metal grid mesh. The enclosure has holes cut for integration with the automated water and air system situated in the rack structure. The filtered air enters the vent on the side of the enclosure using a fan and exits through a second vent below the waste tray. This downward flow of air pushes the waste, including urine, feces, dander, loose fur, glandular secretions, food particles, and food dust, into the waste tray collection unit during microgravity situations similar to the system in the Rodent Habitat Project. ${ }^{18}$ These liquid and solid waste particles would be trapped in this collection unit to prevent any flow into the centralized air filtration unit. The enclosure and waste tray for the demonstration have plastic tabs on the front faces to allow for easy manipulation by the demonstration robot's suction cup end effector.

\section{Model Robotic Platform}

\section{C.1. Moving Platform}

For the maintenance robot to perform its operations on every enclosure, a moving platform system that is able to move vertically, as well as be able to rotate to the adjacent enclosures, was designed. The vertical movement of the system was demonstrated by having four motors with lead crews attached to the maintenance robot's base. The direction and speed of the motors were set at a pace that would allow for the greatest accuracy. Although this system works for the demonstration, it would not be ideal for implementation in the final design. A lead screw has to travel along the entire spacecraft height in order for the maintenance robot to reach all enclosure levels, which is not practical. It adds unnecessary weight and is an obstruction that the robot has to work around, limiting its capabilities.

In addition to the lead screw system for the vertical movement of the robot, a system that rotated the platform was implemented. This was done by mounting the above system on a turntable. A stepper motor with a wheel was then mounted onto the edge of the turntable. As the motor shaft rotated, this caused the entire platform to rotate. This was a simple solution that works for the demonstration model, but is not ideal in a partial-gravity environment. The traction between the motorized wheel and the base platform is heavily based the on the coefficient of friction, which is greatly dependent on the gravitational force.

\section{C.2. Robot Arm}

One of the most important demonstration tasks is showing how the maintenance robot moves the enclosures and carries out certain operations on the enclosure itself, including replacing the food bar, as well as determining the position of the mouse and the ability to handle mice. For purposes of the demonstration, a $\mathrm{UArm}^{66}$ robot outfitted with a suction cup end effector is utilized. This off-the-shelf robot arm has enough capabilities to carry out the procedures necessary for the demonstration. For the robot to carry out these 
procedures, the robot must have a situational awareness feature to determine its own location as well as the location of the enclosures and their tabs. At the beginning of every demonstration, the robot finds its home position. The motors run until they come in contact with various limit switches, zeroing out the positions of the motors. A computer program sends exact steps to the motors, determining where the robot is in relation to the home position. Each enclosure position has a predetermined amount of steps for the robot to travel.

To give the robot arm a wider range of movement, a gear and rack system was implemented. This system allows the robot to reach objects further behind the structure. Once an enclosure is taken out of its slot and moved to another, the robot is then be able to reach objects stored behind the mouse enclosure. This action demonstrates how the robot is able to make necessary repairs to the water delivery system, and air filtration system, which would be located in the logistics section of the spacecraft, behind the enclosures.

\section{Autonomy Demonstration}

\section{D.1. Software Architecture}

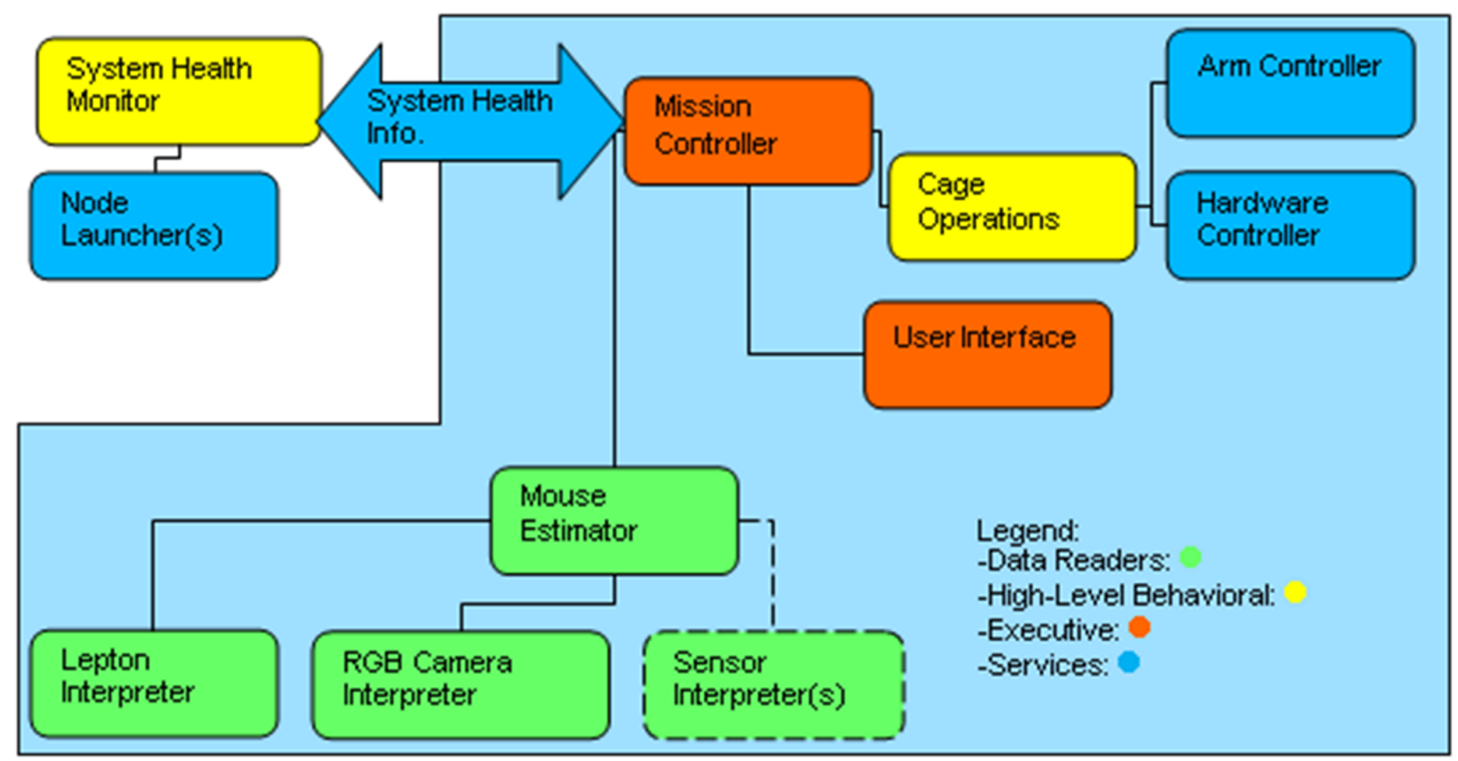

Figure 16. Implementation of the Autonomous Entity Operations Network for the MICEHAB Model Demonstration

The AEON architecture layers described in Autonomous Habitat Functions section II.D.3. are expressed in the MICEHAB autonomy demonstration in the following way (Figure 16):

- Mission Control: This node resides in the Executive Layer, and facilitates high level mission planning and execution.

- User Interface: This node governs user interaction with the system, and makes requests to the Mission Controller for mission changes and interruptions.

- Enclosure Operations: This is a High-Level Behavioral node which translates commands from Mission Control into behaviors used by the Arm Controller and the Hardware Controller.

- Arm Controller and Hardware Controller: These Services act as liaisons between the MICEHAB system and the physical hardware.

- System Health Monitor: This High-Level Behavioral node takes information from each node in the entire architecture concerning its status, and informs the Mission Control of this information.

- Node Launcher(s): These are Services that, using info from the System Health Monitor, manage launching each node when starting the entire MICEHAB system, and also re-launches individual nodes if their health status degrades.

- Lepton/Camera/Sensor Interpreters: These Data Producers interface to sensor hardware to create information regarding the state of the subjects in the experiment.

- Mouse Estimator: This Data Producer combines data from the interpreter nodes to create a combined status that describes the entire state of the mice. 


\section{D.2. Demonstration}

The robot arm moves to a position in front of the target enclosure, and it pulls out the enclosure onto the platform. A red, green, and blue optical camera is mounted on the robot platform that allows the robot to see the tabs of the enclosure when it is in the structure, allowing for the robot to latch onto the tabs via its suction cup and pull out. While the enclosure is fully on the platform, the same visible-light camera is able to see all the contents inside of the enclosure.

Successful and positive interactions between the mice and the robotic arm are vital to the success of the mission. This interaction is demonstrated through use of toy mice. Once both the visible light camera and an adjacent Lepton infrared camera are fully automated through the AEON framework, output from the Camera Interpreters will be sent to the Mouse Estimator in order to determine the location of the toy mouse within the enclosure. The location information is sent to the Mission Controller, which then sends a command to the Arm Controller to pick up the mouse.

Health monitoring is demonstrated using the cameras and a toy mouse outfitted with a heat generating resistor. Through output from the Lepton Camera, the Mission Controller interprets if the temperature of the toy mouse is within defined preset limits. If the temperature is outside of this range, then the robot arm will pick up the toy mouse and simulate transfer of the toy mouse to the medical suite. This demonstrates the ability of the software architecture to autonomously determine if an anomaly exists during regular operations of the robot arm and change to the operation such as taking the mouse to the medical suite.

\section{Summary and Future Work}

Future human exploration missions require the development of capabilities to live independently from Earth. This requires an improved understanding of how the human body reacts to different environments and the development of capabilities to live autonomously (i.e. Earth-independent). MICEHAB is an effective way to demonstrate both of these facets of human exploration. MICEHAB can demonstrate the robotic capabilities to perform preventative and corrective maintenance tasks usually performed by crew aboard the ISS. This is enabled by robotics available in the 2020s that will likely allow real-time processing to collect data and respond accordingly to perform a task. MICEHAB will take advantage of such advanced robotic and autonomy capabilities to operate and maintain an artificial partial gravity rotation facility in cislunar space in order to study the effects of partial gravity on mammalian reproduction and maturation over multiple generations. MICEHAB offers a platform to test exploration-class systems designed to feed forward to human missions to Mars. The facility can be delivered in the mid-2020s as a co-manifested payload on the SLS and will be located near the planned long-duration human habitat so that samples can be transferred to the human habitat for return to Earth. Initial analysis indicates that the MICEHAB facility will likely meet the approximate $10 \mathrm{mT}$ mass requirement for a LDRO injection. Ongoing analyses will adjust the facility design to meet this mass constraint as system designs are refined. Future work includes a detailed definition of the maintenance robotic system aboard MICEHAB based on research and design analysis and work continues on analysis of suitable boom and tether concepts.

\section{Acknowledgments}

The MICEHAB study is funded by a NASA Langley Systems Analysis and Concepts Directorate Investment Fund Award. The team would like to thank Pat Troutman for pontification and spiritual guidance. The team would also like to thank Kara Latorella, Roger Lepsch, Pete Lillehei, John Martin, Dave North, Dave Paddock, and Sam Wald for their invaluable contributions.

\section{References}

\footnotetext{
${ }^{1}$ National Aeronautics \& Space Administration, "Human Exploration and Operations Directorate, Pioneering Space: NASA's next steps on the path to Mars." May 29, 2014, http://www.nasa.gov/sites/default/files/files/Pioneering-spacefinal-052914b.pdf [Accessed: July 1, 2015].

${ }^{2}$ Bobskill, M., Lupisella, M., Mueller, R., Sibille, L., Vangen, S., and Williams-Byrd, J. A., "Preparing for Mars: Evolvable Mars Campaign Proving Ground Approach," IEEE Aerospace Conference, 2015.

${ }^{3}$ Williams-Byrd, J. A., Arney, D. A., Simon, M. A., Rodgers, E. M., Antol, J., and Larman, K., "Implementing NASAs Capability-Driven Approach: Insight into NASAs Processes for Maturing Exploration Systems," 2015 AIAA SPACE Conference E Exposition, 2015.
} 
${ }^{4}$ Ronca, A., Alwood, J., Globus, R., and Souza, K., "Mammalian Reproduction and Development on the International Space Station (ISS): Proceedings of the Rodent Mars III Habitat Workshop," Gravitational and Space Biology,, Vol. 1, No. 1, 2012, pp. 107-123.

${ }^{5}$ National Research Council, Committee for the Decadal Survey on Biological and Physical Sciences in Space, Recapturing a Future for Space Exploration: Life and Physical Sciences Research for a New Era, The National Academy Press, Washington D.C., 2011

${ }^{6}$ Serova, L., Denisova, L., Apanasenko, Z., Kuznetsova, M., and Meizerov, E., "Reproductive function of the male rat after a flight on the Kosmos-1129 biosatellite," Kosm Biol Aviakosm Med., Vol. 16, No. 5, 1982, pp. 62-65.

${ }^{7}$ Keefe, J., "Final Report of the NASA Mammalian Developmental Biology Working Group," Tech. Rep. NASA TM-86756, National Aeronautics and Space Administration, Washington, D.C., 1985.

${ }^{8}$ Tash, J.S., Gupta, V., Holets, L., and Roby, K.F., STS-131: Spaceflight has negative impacts on the morphology, follicle health, and steroid hormone receptors in ovaries and uterine horns in C57Bl/6J mice, IAA Humans in Space Symposium, 2011.

${ }^{9}$ Maese, A.C. and Ostrach, L.H. (Eds.), Neurolab. Final Report for the Ames Research Center Payload. Moffett Field, CA: NASA Ames Research Center, 2002.

${ }^{10}$ Ronca, A.E., Mammalian development in space. Advances in Space Biology and Medicine. 9: 217-251. (Vol 9, Development in Space), 2003.

${ }^{11}$ Wakayama S, Kawahara Y, Li C, Yamagata K, Yuge L, et al., Detrimental Effects of Microgravity on Mouse Preimplantation Development In Vitro. PLoS ONE 4(8): e6753. doi:10.1371/journal.pone.0006753, 2009. 2015].

${ }^{12}$ The Jackson Laboratory, "Mice Database C57BL/6J," http://jaxmice.jax.org/strain/000664.html [Accessed: July 1,

${ }^{13}$ Andreev-Andrievskiy A, Popova A, Boyle R, Alberts J, Shenkman B, Vinogradova O, et al., Mice in Bion-M 1 Space Mission: Training and Selection. PLoS ONE 9(8): e104830. doi:10.1371/journal.pone.0104830, 2014.

${ }^{14}$ Baqai, F.P., Gridley, D.S., Slater, J.M., Luo-Owen, X, Stodieck, L.S., Ferguson, V., Chapes, S.K., and Pecaut, M.J., Effects of spaceflight on innate immune function and antioxidant gene expression, J Appl Physiol., 106(6):1935-42. doi: 10.1152/japplphysiol.91361.2008. Epub 2009 Apr 2, 2009.

${ }^{15}$ Gridley DS, Mao XW, Stodieck LS, Ferguson VL, Bateman TA, Moldovan M, et al., Changes in Mouse Thymus and Spleen after Return from the STS-135 Mission in Space. PLoS ONE 8(9): e75097. doi:10.1371/journal.pone.0075097, 2013.

${ }^{16}$ Behnke, B.J., Stabley, J.N., McCullough, D.J., Davis, III, R.T., et al., Effects of spaceflight and ground recovery on mesenteric artery and vein constrictor properties in mice, FASEB J., January; 27(1): 399409. doi: 10.1096/fj.12-218503, 2013.

${ }^{17}$ R. Lambert, Breeding Strategies for Maintaining Colonies of Laboratory Mice, The Jackson Laboratory, 2007.

${ }^{18}$ National Aeronautics \& Space Administration, Ames Research Center Space Biosciences Division, Rodent Habitat Project, Science Requirements Document Rodent Habitat: Mark-1, Document \# 6075, August 13, 2012.

${ }^{19}$ National Research Council, Guide for the Care and Use of Laboratory Animals, Eighth Edition, The National Academies Press, Washington, D.C., 2011.

${ }^{20}$ University of Michigan Health System, "Transgenic Animal Model Core: Mouse Breeding," 2015, https:// www.med.umich.edu/tamc/breed.html[Accessed: July 1, 2015].

${ }^{21}$ Hall, T. W. "Architectural Considerations for a Minimum Mass, Minimum Energy, Artificial Gravity Environment," 32nd International Conference on Environmental Systems. San Antonio, TX, 2002.

${ }^{22}$ Hall, T. W. "Artificial Gravity Visualization, Empathy, and Design," AIAA Space 2006 Conference and Exposition. San Jose, California, USA, 2006.

${ }^{23}$ Walz, C. "Cygnus Beyond Low-Earth Orbit-Logistics and Habitation in Cis-Lunar Space," NASA Community Workshop on the Global Exploration Roadmap. Baltimore, MD, 2014.

${ }^{24}$ Santucci, D., Francia, N., Trincia, V., Chiarotti, F., Aloe, L., and Alleva, E. "A mouse model of neurobehavioural response to altered gravity conditions: An ontogenetical study," Behavioural Brain Research Vol. 197, No. 1, 2009, pp. 109-118, doi: http://dx.doi.org/10.1016/j.bbr.2008.08.008.

${ }^{25}$ Chen, Y., Huang, R., Ren, X., He, L., and He, Y. "History of the Tether Concept and Tether Missions: A Review," ISRN Astronomy and Astrophysics Vol. 2013, 2013, pp. 1-7. doi: 10.1155/2013/502973.

${ }^{26}$ Cosmo, M. L., and Lorenzini, E. C., eds. Tethers in Space Handbook, 1997.

${ }^{27}$ Hoyt, R. P. "The Cislunar Tether Transportation System Architecture," 2nd Lunar Development Conference. Las Vegas, NV, 2000, pp. 1-12.

${ }^{28}$ Hoyt, R., and Uphoff, C. "Cislunar Tether Transport System," 35th Joint Propulsion Conference and Exhibit. American Institute of Aeronautics and Astronautics, 1999.

${ }^{29}$ Hoyt, R., and Buller, J. "Analysis of the Interaction of Space Tethers with Catalogued Space Objects," 41st AIAA/ASME/SAE/ASEE Joint Propulsion Conference \& Exhibit. American Institute of Aeronautics and Astronautics, 2005.

${ }^{30}$ Johnson, L., Young, R., Montgomery, E., and Alhorn, D. "Status of solar sail technology within NASA," Advances in Space Research Vol. 48, No. 11, 2011, pp. 1687-1694.

${ }^{31}$ Mikulas, M. M., Collins, T. J., Doggett, W., Dorsey, J., and Watson, J. "Truss Performance and Packaging Metrics," AIP Conference Proceedings Vol. 813, No. 1, 2006, pp. 1000-1009.

${ }^{32}$ Stillwagen, F., Garn, P., Smith, K., Cornelius, D. \& Goodliff, K., SPASIM (SPAcecraft SIMulator) [Computer software]. NASA Langley Research Center. Hampton, 2004.

${ }^{33}$ Wireless, G. (2004). Standard Parabolic Antennas: Diameters, Weights, and Electrical Specifications. Chicago: GSN.

${ }^{34}$ Bagri, D. (2008). Pros and Cons of Using Arrays of Small Antenna vs Large-Single Dish Antennas for DSN. Pasadena: NASA.

${ }^{35}$ Gutierrez-Luaces, B. (1997). Radio Astronomy Use of Space Research (Deep-Space) Bands in the Shielded Zone of the Moon. Bellevue: TMO Plans and Commitments Office. 
${ }^{36}$ Wertz, L. "Communications Architecture," in Space Mission Analysis and Design, El Segundo, Microcosm Press, Kluwer Academic Publishers, pp. 533-584., 1999.

${ }^{37}$ Klovstad, J.J., Jones, C.A., Rodgers, E.M., and Simon, M.A., Breeding Rodents Extraterritorially to Enable Discovery (BREED) [Computer Software]. NASA Langley Research Center, Hampton, VA, 2015.

${ }^{38}$ The Jackson Laboratory, "Body weight information: JAX Mice Strain C57BL/6J," http://jaxmice.jax.org/support/ weight/000664.html[Accessed: July 1, 2015].

${ }^{39}$ Slaba, T.C., Mertens, C.J., and Blattnig, S.R., Radiation Shielding Optimization on Mars, National Aeronautics and Space Administration, Langley Research Center, Hampton, Virginia, NASA/TP2013-217983, April 2013.

${ }^{40}$ Cucinotta, F.A., Kim, M.Y., Chappell, L.J., Evaluating Shielding Approaches to Reduce Space Radiation Cancer Risks. NASA Technical Memorandum 2012-217361, 2012.

${ }^{41}$ Wilson, J.W., Miller, J., Konradi, A., Cucinotta, F.A., eds. Shielding Strategies for Human Space Exploration. NASA Conference Publication 3360, 1997.

${ }^{42}$ Wilson, J.W., Clowdsley, M.S., Cucinotta, F.A., Tripathi, R.K., Nealy, J.E., De Angelis, G., Deep Space Environments for Human Exploration. Advances in Space Research, Volume 34, pp. 1281-1287, 2004.

${ }^{43}$ Hayar, A., Bryant, J.L., Boughter, J.D., and Heck, D.H.. A low-cost solution to measure mouse licking in an electrophysiological setup with a standard analog-to-digital converter. J. Neurosci Methods, 153(2): 203207, 2006.

${ }^{44}$ National Aeronautics \& Space Administration, A Researchers Guide to: International Space Station Rodent Research, NP-2015-03-016-JSC, 2013.

${ }^{45}$ Sherwin, C., "Comfortable Quarters for Mice in Research Institutions," http://awionline.org/pubs/cq02/Cqmice.html[Accessed: July 1, 2015].

${ }^{46}$ National Aeronautics \& Space Administration, Rodent Habitat Science Working Group, Rodent Research Science Requirements Envelope Document (SRED), Document \# 341, August 11, 2013.

${ }^{47}$ Zoccolan, D., Graham, B. J., Cox, D. D., A Self-Calibrating, Camera-Based Eye Tracker for the Recording of Rodent Eye Movements, Frontiers in Neuroscience, 4, 193, 2010.

${ }^{48}$ Stahl, J.S., van Alphen, A. M., De Zeeuw, C. I, A comparison of video and magnetic search coil recordings of mouse eye movements, Journal of Neuroscience Methods, Volume: 99, 2000.

${ }^{49}$ Bronson, F., Dagg, C., and Snell, G., "Reproduction," Biology of the Laboratory Mouse, http:// www.informatics.jax.org/greenbook/frames/frame11.shtml [Accessed: July 1, 2015].

${ }^{50}$ Connor, A., "Auroras Guide to Mouse Colony Management," Cell Migration Gateway, http://www.cellmigration.org/ resource/komouse/protocols/mouse_management_feb06.pdf [Accessed: July 1, 2015].

${ }^{51}$ Ambrose, R.O., SS-Space Technologies for the Offshore Deepwater Industry: Robotic Solutions for Exploration, Earth and Space, Offshore Technology Conference, OTC-25881-MS, Houston, TX, May 4-7, 2015.

${ }^{52}$ Diftler, et al., DOI: 10.1109/ROBOT.2003.1241975 Conference: Robotics and Automation. Proceedings, ICRA '03. IEEE International Conference on, Volume: 2, 2003.

53 "Laboratory animal management robot can care for 30,000 mice," DigInfoTV, http://www.diginfo.tv/v/13-0053-ren.php [Accessed: July 1, 2015].

${ }^{54}$ MWPVL International, Inc., Dematic Multishuttle 2, An In-depth and Independent Review from a Supply Chain Consultant, March, 2013.

55 "da Vinci Surgery Fact Sheet," Intuitive Surgical, http://www.davincisurgery.com/assets/docs/da-vinci-surgeryfact-sheet-en-1005195.pdf [Accessed: July 1, 2015].

56 "M7 Surgical Robot," SRI International, http://www.sri.com/engage/products-solutions/m7-surgical-robot [Accessed: July 1, 2015].

${ }^{57}$ National Cancer Institute. NCI Cancer Bulletin. Tracking the Rise of Robotic Surgery for Prostate Cancer. Vol. 8/Number 16, Aug. 9, 2011.

${ }^{58}$ Haidegger,T. and Zoltan, B. Surgical robotic support for long duration space missions, Acta Astronautica, Volume 63, Issues 710, 2008.

${ }^{59}$ Wolterink-Donsealaar, I.G., Meerding, J.M., Fernandes, C., A method for gender determination in newborn dark pigmented mice., Lab Amin, 2009.

${ }^{60}$ Byers, S. L., Wiles, M. V., Dunn, S. L., and Taft, R. A., Mouse Estrous Cycle Identification Tool and Images, PLoS One, 2012.

${ }^{61}$ Doarn, C.R., Anvari, M., Low, T., and Broderick, T.J., Evaluation of Teleoperated Surgical Robots in an Enclosed Undersea Environment, Telemed J E Health., 15(4):325-35, 2009.

${ }^{62}$ Wortman, T.D., Mondry, J.M., Farritor, S.M., and Oleynikov, D. Single-site colectomy with miniature in vivo robotic platform, IEEE Trans Biomed Eng., 60(4):926-9, 2013.

${ }^{63}$ Lackas, K.M., Design and Assembly of Parabolic Flight Payload to Evaluate Miniature in vivo Surgical Robots in Microgravity, University of Nebraska-Lincoln, Masters dissertation, 2014.

${ }^{64}$ Neilan, J., Cross, C., Motter, M., Tran, L Qualls, G., Rothhaar, P., Trujillo, A., Allen, D., Using Multimodal Input for Autonomous Decision Making for Unmanned Systems, Aviation 2015, Dallas, TX.

${ }^{65}$ Cross, C., Motter, M., Neilan, J., Tran, L Qualls, G., Rothhaar, P., Trujillo, A., Allen, D., its Difficult to work in groups when youre Omnipotent, So dont be An Open, Distributed Software Architecture for UXS Operations, Aviation 2015, Dallas, TX.

66 "UArm Metal," UFactory, http://store.ufactory.cc/uarm-metal/ [Accessed: July 1, 2015]. 